\title{
HYDROGEN SULPHIDE CORROSION OF CARBON AND STAINLESS STEEL ALLOYS IMMERSED IN MIXTURES OF RENEWABLE FUEL SOURCES AND TESTED UNDER CO-PROCESSING CONDITIONS
}

\author{
András Gergely,,${ }^{1}$ Roland Locskal, ${ }^{1}$ Péter Szabó, ${ }^{2}$ Antal KróJer,${ }^{3}$ And TAmÁs KRIstó ${ }^{1}$ \\ ${ }^{1}$ Department of Physical Chemistry, Institute of Chemistry, University of Pannonia, Egyetem u. 10, \\ Veszprém, 8200, HUNGARY \\ ${ }^{2}$ Department of General and Inorganic Chemistry, Institute of Chemistry, University of Pannonia, \\ Egyetem u. 10, Veszprém, 8200, HUNGARY \\ ${ }^{3}$ Department of Inspection and Maintenance, MOL Co., Olajmunkás u. 2, Százhalombatta, 2443, \\ HUNGARY
}

\begin{abstract}
In accordance with modern regulations and directives, the use of renewable biomass materials as precursors for the production of fuels for transportation purposes is to be strictly followed. Even though, there are problems related to processing, storage and handling in wide range of subsequent uses, since there must be a limit to the ratio of biofuels mixed with mineral raw materials. As a key factor with regards to these biomass sources pose a great risk of causing multiple forms of corrosion both to metallic and non-metallic structural materials. To assess the degree of corrosion risk to a variety of engineering alloys like low-carbon and stainless steels widely used as structural metals, this work is dedicated to investigating corrosion rates of economically reasonable engineering steel alloys in mixtures of raw gas oil and renewable biomass fuel sources under typical coprocessing conditions. To model a desulphurising refining process, corrosion tests were carried out with raw mineral gasoline and its mixture with used cooking oil and animal waste lard in relative quantities of $10 \%(\mathrm{~g} / \mathrm{g})$. Co-processing was simulated by batch-reactor laboratory experiments. Experiments were performed at temperatures between 200 and $300^{\circ} \mathrm{C}$ and a pressure in the gas phase of 90 bar containing $2 \%\left(\mathrm{~m}^{3} / \mathrm{m}^{3}\right)$ hydrogen sulphide. The time span of individual tests were varied between 1 and 21 days so that we can conclude about changes in the reaction rates against time exposure of and extrapolate for longer periods of exposure. Initial and integral corrosion rates were defined by a weight loss method on standard size of coupons of all sorts of steel alloys. Corrosion rates of carbon steels indicated a linear increase with temperature and little variation with composition of the biomass fuel sources. Apparent activation energies over the first 24-hour period remained moderate, varying between 35.5 and $50.3 \mathrm{~kJ} \mathrm{~mol}^{-1}$. Scales developed on carbon steels at higher temperatures were less susceptible to spall and detach. Nonetheless, moderate deceleration of corrosion rates as a function of time are due to the less coherent, frequently spalling and low compactness, higher porosity of the scales evolved at lower and higher temperatures, respectively. On the surface of high alloy steels, sulphide scales of an enhanced barrier nature formed during the induction periods and the layer formation mechanism was found to be assisted by the increasing temperature as initial reaction rates considerably decreased over time. Nevertheless, corrosion-related sulphide conversion of metals and mass loss of the high alloys are strongly affected by the composition of the biomass fuel sources especially animal waste lard. Thermal activation in the first 24 hours decreased from 68.9 to $35.2 \mathrm{~kJ} \mathrm{~mol}^{-1}$. A greater degree of failure to develop protective sulphide scales was experienced by changing to composition of the biomass fuel sources than the impact of thermal activation between a narrow temperature range at around $100^{\circ} \mathrm{C}$. In accordance with the literature, high free fatty acid contents lead to high corrosion rates accounted for direct corrosion of high alloy steels and assisted solubilisation of corrosion products. In addition, the pronounced acceleration of sulphide corrosion is connected to the diminishing inhibition effect of the sulphide scales.
\end{abstract}

Keywords: Hydrogen sulphide corrosion, gas phase corrosion, carbon and high alloy steels, renewable biofuels, used cooking oil, animal waste lard

\section{Introduction}

In an increasing power-hungry society coupled with the age of unprecedented global warming, the relevance of the substitution of fossil fuels from mineral sources and their mixtures with materials obtained from renewable biomass sources in the highest possible proportions is

*Correspondence: gergelyandras432@gmail.com one of the most urgent priorities for current and future generations to observe. Sustainable biomass resources, vegetable oils, and waste lard are renewable feedstocks for partial substitution of mineral oils in production of biofuels. Although their availability is limited at present, there are clear benefits of biofuel production, namely meeting local consumption demands, reduced emissions of greenhouse gases during transportation over long distances in supply chains. In addition, the lower dependence on fossil fuels unequivocally contributes to increased national security. By 2010 , the 
European Commission set a goal that EU biofuels must account for $5.75 \%$ of transportation fuels. Biodiesel as a mono-alkyl ester of vegetable oils and waste lard [1-3] is distinguished from second-generation type renewable feedstocks of inedible oils and algae. Using vegetable oils, composed of a majority of natural triacylglycerols in similar to waste lard, biodiesel production involves processing by either trans-esterification with methanol or ethanol besides production of glycerol or catalytic hydrocracking. The latter is an economically more feasible option given the absence of investment costs [4, 5] as no dedicated facility is required [6]. Cracking, pyrolysis, catalytic hydrodesulphurisation (HDS), deoxygenation [7], and the saturation of olefins and aromatics favour the production of ultra-low sulphur petrodiesel $[8,9]$. The fuel derived from lipid feedstock of biological sources emulating the composition of petro-diesel is renewable diesel. Several crops such as rapeseed, soybean, palm, sunflower, etc. are excellent renewable oil sources recycled for energy storage and production lines, currently maize is the most frequently used feedstock for biofuel production primarily due to its high profitability. However, when the profit margin is a priority, used cooking oil trumps virgin vegetable oils, since it is around three times cheaper. As for the chemical stability aspects, fossil fuels containing methyl esters of fatty acids are less oxidation-resistant and more hygroscopic, so their long-term storage is not recommended. To process biomass in conventional oil refineries, vegetable oil and vacuum gas oil mixtures are preferred for quality diesel production [10, 11] as hydrotreating the latter along with heavy gas oil results in normal alkanes of $\mathrm{C} 15-\mathrm{C} 18$ [12]. Moderate reaction temperatures yield diesel, while higher temperatures lead to gasoline production. Technological parameters of hydroprocessing under mild conditions [13] generally mean temperatures of $320-430^{\circ} \mathrm{C}$ and pressures of $3.5-$ $5.5 \mathrm{MPa}$ with a relative quantity of the biomass source of $\sim 5.5 \%$. High isoparaffin content is obtained by catalytic hydrogenation of triglycerides stemming from waste lard [14]. Nevertheless, there are vegetable oils (tall oil) that have high fatty acid contents [15-19] similar to waste lard. If they are not processed properly, they will be corrosive in nature in subsequent applications. Their conversion to liquid hydrocarbons by catalytic hydrocracking seems a viable option. Nevertheless, aside from indispensable processes relating to biomass-based fuel production, all sorts of sources including biofuels are to be refined to decrease heteroatom content, such as sulphur, nitrogen and phosphorous, which might be potential sources of pollutants. To preserve safety and profitability one should consider possible corrosion risks of coprocessing of renewable fuel sources to metallic structures from which equipment of existing petroleum refineries has been built and used for decades.

Industrial methods and technological means to protect oil production equipment were reviewed in terms of corrosion protection [20]. In relation to highly corrosive effects caused by waste lard, it depends on the quantity and composition of free fatty acids as a way of dissolution of metal-acid complexes coupled with reduction of a depolarisator. Some fatty acids, such as stearic, palmitic, myristic and lauric acid, are even used for heat storage systems and their corrosivity is enhanced by thermal cycling [21]. Acceptable resistance of the 304L stainless steel (1.4307) and an aluminium alloy with passive oxide layers on their surfaces was pointed out. The kinetics of naphthenic acid and sulphide corrosion and their interactions with Q235 and $5 \mathrm{Cr} 1 / 2 \mathrm{Mo}$ steel alloys were investigated at $270^{\circ} \mathrm{C}$ in oil with naphthenic acid and sulphur contents of up to $1.0 \%$ $(\mathrm{g} / \mathrm{g})$ as synthetic refining media [22]. In the liquid phase with naphthenic acids at $230^{\circ} \mathrm{C}$, the low alloy and carbon steels indicate nearly the same naphthenic corrosion rates but above $230^{\circ} \mathrm{C}$ the former gave higher rates. This is attributed to its higher activation energy $\left(63 \mathrm{~kJ} \mathrm{~mol}^{-1}\right)$ compared to that of carbon steel (54 $\mathrm{kJ} \mathrm{mol}^{-1}$ ) leading to greater acceleration with increasing temperature. In dimethyl disulphide containing oil, sulphide corrosion follows parabolic kinetics. Film growth was faster on carbon steel than on low alloy steel. In oil containing naphthenic acids and dimethyl disulphide, low alloy steel showed lower corrosion rates than carbon steel; thus, sulphide corrosion proved to be rate-governed by pseudo-passive films. Different resistance of the alloys was connected to the chromium sulphide $\left(\mathrm{Cr}_{5} \mathrm{~S}_{8}\right)$ in the pseudo-passive film formed on low alloy steel, in contrast with pyrrhotite $\left(\mathrm{Fe}_{7} \mathrm{~S}_{8}\right)$ and troilite $(\mathrm{FeS})$ films obtained on carbon steel. At oil refineries, especially in the HDS streamline part, the rate of metal loss either in the form of general or local corrosion is one of the highest. Thus, to achieve an optimal balance between production, inspection and maintenance careful planning is required.

Aside from works on corrosion risks of biofuels at low temperatures without the presence of hydrogen sulphide rather for the automotive than refining industry, to our best knowledge, there is a rather limited number of studies in the literature to date, giving insights into either the corrosion rates of engineering alloys or the integrity risk assessment of plant equipment regarding the HDS co-processing of renewable fuel sources such as used cooking oil and waste lard in low proportion mixtures with raw gas oils in refining plants originally designed to withstand mineral oils. Therefore, the aim of this work is to investigate corrosion rates of inexpensive engineering alloys, two types of carbon steels (1.0425 and St35.8) and a low alloy steel sample (1.7335), which are all basic materials of heat-resistant tube and pipe systems. In addition, for the purpose of making a comparison, as structural materials of absorbers, strippers, and overlays in reactors, three high alloy steel samples (1.4541, $1.4571,1.4401)$ were selected for hydrogen sulphide corrosion, tested at a pressure of 90 bar and temperatures between 200 and $300^{\circ} \mathrm{C}$. Under the aforementioned parameters, hydrogen sulphide and naphthenic acid corrosion of steel alloys are investigated focusing on the dependence of corrosion rates on temperature and time. 
Table 1. Chemical compositions of autoclave experiment-tested steel alloys in weight percent ( $\mathrm{Fe}$ in balance).

\begin{tabular}{cccccccccccc}
\hline Alloys & $\mathrm{C}$ & $\mathrm{Cu}$ & $\mathrm{Si}$ & $\mathrm{P}$ & $\mathrm{S}$ & $\mathrm{Mn}$ & $\mathrm{Cr}$ & $\mathrm{Ni}$ & $\mathrm{Mo}$ & $\mathrm{N}$ & $\mathrm{Ti}$ \\
\hline 1.0425 & $\leq 0.20$ & $\leq 0.30$ & $\leq 0.40$ & $\leq 0.025$ & $\leq 0.015$ & $\leq 0.80-1.40$ & $\leq 0.30$ & $\leq 0.30$ & $\leq 0.08$ & $\leq 0.012$ & $\leq 0.03$ \\
$\mathrm{St35.8}$ & & & $0.10-0.35$ & $\leq 0.04$ & $\leq 0.04$ & $0.40-0.80$ & & & & & \\
1.7335 & $\leq 0.08-0.18$ & $\leq 0.30$ & $\leq 0.35$ & $\leq 0.025$ & $\leq 0.01$ & $0.4-1.0$ & $0.70-1.15$ & & 0.5 & & 0.012 \\
1.4541 & $\leq 0.06$ & & $\leq 0.75$ & $\leq 0.04$ & $\leq 0.015$ & $\leq 2.0$ & $17.0-19.0$ & $9.0-11.0$ & - & & $5^{*} \mathrm{C}-0.70$ \\
1.4571 & $\leq 0.08$ & & $\leq 1.0$ & $\leq 0.045$ & $\leq 0.015$ & $\leq 2.0$ & $16.5-18.5$ & $10.5-13.5$ & 2.5 & & $5^{*} \mathrm{C} \leq 0.70$ \\
1.4401 & $\leq 0.07$ & & $\leq 1.0$ & $\leq 0.045$ & $\leq 0.03$ & $\leq 2.0$ & $16.5-18.5$ & $10.0-13.0$ & 2.5 & $\leq 0.1$ & \\
\hline
\end{tabular}

\section{Experimental}

In processing technology before the hydrotreating reactor is heated to $\sim 420^{\circ} \mathrm{C}$, generally the high proportions of unsaturated and saturated free fatty acids cause the main corrosion problem, after that hydrogen sulphide is usually responsible for most of the corrosion risks. Therefore, experiments were planned to satisfy the goals of investigating the corrosion rates of engineering steel alloys representative of materials in HDS plants caused by the evolution of hydrogen sulphide during processes, combined with the increased risks exerted by the mixture of used cooking oils and animal fats that should all be co-processed in the same plant altogether under the same conditions.

Batch type experiments were carried out in two reactors with a wall thickness of $25 \mathrm{~mm}$ (manufactured by Lampart Vegyipari Gépgyár Zrt) having internal sizes of 2 and 4 litres. The temperature was measured inside the reactors through a stainless steel tube casing leading from the head into the core of the inner volume, with platinum 100 resistive thermometers and adjusted with HAGA KD481DD controllers within $\pm 6^{\circ} \mathrm{C}$ after auto-tuning refining with liquid- and gas-filled reactors at pressure targets. Heating of the reactors was performed with 6 resistance-heating wires, which were evenly distributed around the encasings wrapped in a 4 $\mathrm{cm}$ thick thermo-insulation layer of glass wool lined inside steel scaffolds. The apparent effective performance of the heating systems with power consumptions of 3.7 and $6 \mathrm{~kW}$ at $3 * 380 \mathrm{~V}$ and drew currents of 4.5 and 7.2 A to the small and large reactors, respectively. Heat ramp and cooling down phases of batch-type experiments were carried out as rapidly as possible especially in the cases of the 24- and 72-hour tests. Fast temperature ramp ups were achieved by providing the highest laboratory temperature and the close location of the nearby working reactor to utilise its dissipated heat (initial pressure was corrected for fillups). During cooling down phases at the end of corrosion tests, reactor encasings were removed from scaffolds. The inside pressure was slowly reduced by letting the gas slowly out of the reactor through pressure valves so that gas phase reactions were frozen within the shortest possible period. The time when the temperature decreased to $200^{\circ} \mathrm{C}$ and/or the gas pressure dropped to at least $70 \%$ of its initial target was regarded as the end time of reactor experiments. Short stainless steel tubes (outer- and inner-diameters of 6 and $4 \mathrm{~mm}$ ) were employed for fill-ups and long ones for the evacuation of reactor gases. For safety reasons, used reactor gases still containing about $2 \% \quad\left(\mathrm{~m}^{3} / \mathrm{m}^{3}\right)$ hydrogen sulphide werße led over several steps through Erlenmeyer flasks containing an aqueous solution of sodium bicarbonate with a moderately high $\mathrm{pH}$ to work as alkaline absorbers.

Coupons of steel alloys of a standard size $(32 \mathrm{~mm}$ outer- and $10.5 \mathrm{~mm}$ inner-diameters with a thickness of $2 \mathrm{~mm}$ ) were used for the experiments. All coupons were grated and polished with silicon carbide emery papers (\#400 and \#600) soaked in water to remove rust and stain spots. Then they were ultrasonicated twice for 5 minutes in isopropanol and acetone. The cleaning process obeyed and adapted principles of the ASTM G1 standard ('Standard practice for preparing, cleaning, and evaluating corrosion test specimens'). After drying, mass of the coupons was measured with an analytical balance. Compositions of the investigated steel alloys are summarised in Table 1. With proper engravings, coupons were assembled on glass rods, each with annular glass cylinders ( $8 \mathrm{~mm}$ long) for proper spacing. Then glass rods with steel alloys were inserted into large glass tubes holding the media of raw or refined gas oil and its mixture with used cooking oil (UCO in $10 \%(\mathrm{~g} / \mathrm{g}))$ or waste lard (WL in $10 \%(\mathrm{~g} / \mathrm{g}))$. The composition of gas oil and renewable sources, supplied by the Department of Analytics and the Institute of Biotechnology, and Bay Zoltán Non-profit Ltd. for Applied Research, are summarised in Table 2. Animal waste lard was one of the most corrosive types available in the region owing to its high free fatty acid content. All materials were supplied by MOL Co., Hungary. Glass tubes accommodated five coupons (parallel samples) four times (according to the four different chemical compositions of steel alloys). When integral corrosion rates were defined for a time period by weight loss measurements, the standard deviation was also assessed by the 5 parallel specimens. Error bars in figures based on gathered data are directly related to the standard deviation of population samples of the experiments obtained by five coupons in one autoclave test. The level of the fluids was set well above the upper coupons. To minimize loss of the fluids owing to evaporation especially around $300^{\circ} \mathrm{C}$ despite the high pressure, inner and outer glass caps were employed for each glass tube. Glass caps with an appropriate figure did not hinder efficient gas diffusion into sample holder glass tubes, ensuring good access to the fluids and steel coupons. 
Table 2. Basic characteristics of the renewable biomass fuel sources and distillation data of raw gas oil.

\begin{tabular}{|c|c|c|c|c|}
\hline $\begin{array}{l}\text { Fuel } \\
\text { source }\end{array}$ & Used cooking oil & Animal waste lard & $\begin{array}{l}\text { Distillation data } \\
\text { of raw gas oil } \\
\text { Boiling point of } \\
\text { fractions }\end{array}$ & $\begin{array}{l}\text { Proportion of } \\
\text { fractions }\end{array}$ \\
\hline Organic acids $\left(\mathrm{C} 1-\mathrm{C} 4, \mathrm{mg} \mathrm{kg}^{-1}\right)$ & & & 136.4 & Initial \\
\hline Citric acid & 1.90 & - & 187.2 & 5 \\
\hline Lactic acid & 32.69 & - & 197.3 & 10 \\
\hline Formic acid & 8.46 & - & 214.1 & 20 \\
\hline Acetic acid & 64.43 & 94.13 & 227.6 & 30 \\
\hline Isobutyric acid & 0.00 & 30.83 & 241.8 & 40 \\
\hline Butyric acid & 27.69 & 175.58 & 258.2 & 50 \\
\hline Organic acids $\left(\mathrm{C} 8-\mathrm{C} 20, \mathrm{mg} \mathrm{kg}^{-1}\right)$ & & & 274.2 & 60 \\
\hline Caprylic acid & 1 & 1.5 & 291.5 & 70 \\
\hline Capric acid & - & 1 & 310.9 & 80 \\
\hline Lauric acid & 2 & 1 & 331.9 & 90 \\
\hline Myristic acid & 3 & 11 & 347.3 & 95 \\
\hline Palmitoleic acid & 2.5 & 18 & Recovery & 96.7 \\
\hline Heptadecanoic acid & - & 3.5 & Residue & 1.5 \\
\hline$\gamma$-linoleic acid & 0.6 & 5 & Loss & 1.8 \\
\hline Arachidic acid & - & 3.5 & - & - \\
\hline Gondoic acid & - & 7.5 & - & - \\
\hline Nervonic acid & - & 1 & - & - \\
\hline Palmitic acid & 100 & 165 & - & - \\
\hline Stearic acid & 25 & 95 & - & - \\
\hline Oleic acid & 285 & 310 & - & - \\
\hline Linoleic acid & 190 & 65 & - & - \\
\hline \multicolumn{5}{|l|}{$\begin{array}{c}\text { Extractable petroleum } \\
\text { Hydrocarbons }\left(\mathrm{C} 10-\mathrm{C} 40, \mathrm{mg} \mathrm{kg}^{-1}\right)\end{array}$} \\
\hline C 36 & 1.15 & 0.30 & - & - \\
\hline $\mathrm{C} 37$ & 0.10 & - & - & - \\
\hline $\mathrm{C} 38$ & 0.15 & 0.24 & - & - \\
\hline C39 & 0.12 & - & - & - \\
\hline Iodine number $\left(10^{-2} \mathrm{mg} \mathrm{g}^{-1}\right)$ & 96 & 65 & - & - \\
\hline Total acid number $\left(\mathrm{KOH} \mathrm{mg} \mathrm{g}{ }^{-1}\right)$ & 6 & 74 & - & - \\
\hline \multicolumn{5}{|l|}{ Alcohol components $\left(\mathrm{mg} \mathrm{kg}^{-1}\right)$} \\
\hline Glycerol & - & 7014.05 & - & - \\
\hline Methanol & - & 100.33 & - & - \\
\hline Ethanol & 11.12 & 6.35 & - & - \\
\hline Water content $\left(\mathrm{mg} \mathrm{kg}^{-1}\right)$ & 611 & 1171 & - & - \\
\hline \multicolumn{5}{|l|}{$\begin{array}{l}\text { Metals \& other elements } \\
\text { as impurities }\end{array}$} \\
\hline $\mathrm{Al}$ & 0.02 & 0.016 & - & - \\
\hline $\mathrm{Fe}$ & 0.001 & 0.004 & - & - \\
\hline $\mathrm{Na}$ & 0.005 & 0.740 & - & - \\
\hline $\mathrm{P}$ & - & 0.021 & - & - \\
\hline $\mathrm{S}$ & - & 0.038 & - & - \\
\hline $\mathrm{K}$ & - & 0.021 & - & - \\
\hline $\mathrm{Ca}$ & - & 0.036 & - & - \\
\hline Amino acids (in $\% \mathrm{~g} / \mathrm{g}$ ) & -- & Less than 0.3 & - & - \\
\hline
\end{tabular}

For the experiments, bottled hydrogen gas (2.5ip, with a purity of $99.5 \%$ ) with an initial pressure of 150 bar (provided by Messer Hungarogáz Kft.) was used as received to fill up reactors at around room temperature (or the temperature when the experiment started). Initial fill-up pressures were calculated according to the pressure of hydrogen refining at the target temperature according to the p-V-T database [23]. There were pressure increments almost in all experiments, which were caused by the varying volatility of raw and refining gas oil phases. Hence real pressure of reactor gas phases was recorded during the experiments. The mixtures of gas oil and used cooking oil or animal fats were not so volatile as pure gas oil so pressure increases were less pronounced with those materials. At the time of filling up, the gas pressure inside the reactors was measured both by a reductor (200/200, supplied by Messer Hungarogáz Kft.) and pressure gauges (MERRKFM PRLT S91, pressure measuring was calibrated before and after experiments) nested in reactor heads.

For practical and safety reasons, hydrogen sulphide of stoichiometric quantity was in situ produced from elemental sulphur. The quantity of hydrogen sulphide was calculated to be $\sim 2$ percent by volume in all autoclave experiments at the target pressure, but the overall pressure was greater because of the changing volatility of the organic fluid phases. Thus, the pressure in autoclave experiments was higher than the hydrogen 
sulphide contents would have been lower with a maximum of $15 \%$, but stoichiometric quantities were initially set with an excess of $10 \%$ in the experiments so the concentration of $2 \%\left(\mathrm{~m}^{3} / \mathrm{m}^{3}\right)$ was considered to be assured. Before the series of autoclave experiments, blind tests were performed to validate the proportion of hydrogen sulphide of the gas phase ( 2 volume percent) after an induction time of one hour at a temperature of $250^{\circ} \mathrm{C}$ and at least 40 bar of pressure. The reactor gas was diluted by 100 times with a nitrogen stream then the mixture was entrained into a Draeger X-am 5600 $\mathrm{H}_{2} \mathrm{~S}$ detector to validate the hydrogen sulphide contents of the reactors.

After continuous decompression at the end of the autoclave experiments, reactor heads were removed then glass tube holders (made of stainless steel) with the fluid and steel samples were gathered. Depending on the kind of alloy, the heavy oil and greasy residue of steel coupons were removed with paper towels then purification was performed three times for 10 minutes each using ultrasonication to eliminate traces of organic phases. Sulphide corrosion scale was removed by careful polishing, while continuously monitoring the surface for intact metallic steel. The use of Clark's solution was attempted to use but it proved to be inefficient in cleaning metal sulphides first rather than attacking some of the remaining metallic parts of steel coupons near the surface. The masses of the coupons were measured on the same analytical balance as before the tests then by relying on the weight loss method corrosion rates were assessed for the measured periods. In almost all experiments, high mass changes were obtained with low relative variance of data. Corrosion tested coupons were not investigated for internal penetration forms of corrosion products deep inside the bulk lattice and the corrosion of grain boundaries, only external corrosion scale products were analysed.

Although the temperature highly impacts the efficiency of hydroprocessing of biomass sources and composition of diesel fuels [24] at the proposed target temperature of $420^{\circ} \mathrm{C}$ and pressure of 100 bar to reproduce original conditions, severe limitations were faced because of the rapid coke formation from the mixture of raw gas oil with used cooking oil and animal fat, yield complete conversion within less than 24 hours. This made it impossible to carry out experiments at such a high temperature. Therefore, the temperature rage had to be compromised and balanced with the dwelling time of the samples. Then, all experiments could be carried out without any noticeable loss of the organic fluid phase caused by evaporation or cock deposition.

\subsection{X-ray diffraction}

After reactor testing, spalled layers were crushed. The powdered and low adhering sulphide scales were scrubbed, gathered, and purified twice over 10 minutes each using ultrasonication in isopropanol.

XRD analysis was performed using a Philips PW 3710 type powder diffractometer equipped with a PW 3020 vertical goniometer and curved graphite diffracted beam monochromator. The radiation applied was $\mathrm{CuK} \alpha$ from a broad-focus $\mathrm{Cu}$ tube, operating at $50 \mathrm{kV}$ and 40 $\mathrm{mA}$. Samples were measured in a continuous scan mode with a $0.02^{\circ} \mathrm{s}^{-1}$ scanning rate. Data collections and evaluations were carried out with X'Pert Data Collector and X'Pert High Score Plus software.

\subsection{Scanning Electron Microscopy and Energy Dispersive Spectroscopy}

At the end of reactor testing, steel coupons containing multiple layers of low-adhering sulphide scales and powders gathered from removed surface scales were purified twice over 10 minutes each using ultrasonication in isopropanol. The morphology of corroded steel coupons was measured with a scanning electron microscope (SEM, Philips XL31 ESEM) in the secondary electron mode with an accelerating voltage of $20 \mathrm{kV}$ and recording images produced by back-scattered electrons, as well. For rough elemental analysis, energydispersive X-ray spectroscopy (EDS) was also carried out.

\subsection{Micro-Raman Spectroscopy}

After gathering the metal coupons from fuel mixtures and removing the traces of organic phases twice of over 5 minutes each using ultrasonication both in isopropanol and acetone, sulphide scales were probed five times at different spots on the surface. Raman measurements were performed at atmospheric pressure and gas composition. A Bruker SENTERRA Raman microscope was used to analyse samples. The source was a green semiconductor laser with a diameter of $532 \mathrm{~nm}$ and a maximum power of $10 \mathrm{~mW}$. For the microscope, a 10x objective was used. Raman signals were collected with a thermoelectrically-cooled charge-coupled device detector and recorded for typically 15 scans. The typical integration time to record Raman spectra was $15 \mathrm{~s}$ on average with a spectral resolution of $4 \mathrm{~cm}^{-1}$.

\section{Results and Analysis}

\subsection{Reactor Experiments}

Temperature dependence of the corrosion rates of steel alloys immersed in raw gas oil and its mixtures with renewable biomass sources are presented in Fig. 1. Over a narrow temperature range of $100^{\circ} \mathrm{C}$, the 1.0425 carbon steel indicated saturation of sulphidation rates at $275^{\circ} \mathrm{C}$ in all organic fluids. Corrosion rates in raw gas oil at $300^{\circ} \mathrm{C}$ remained similarly high but in used cooking oil and waste lard mixtures decreased beyond a random scatter of data. The St35.8 carbon steel indicated a similar trend. In case of the 1.7335 carbon steel, the highest corrosion rates were obtained with almost linear relationship between the reaction rate and temperature. Reaction rates over the entire temperature range were the least affected by the types of organic fluids. As expected, the 1.4541 high alloy steel gave the lowest 


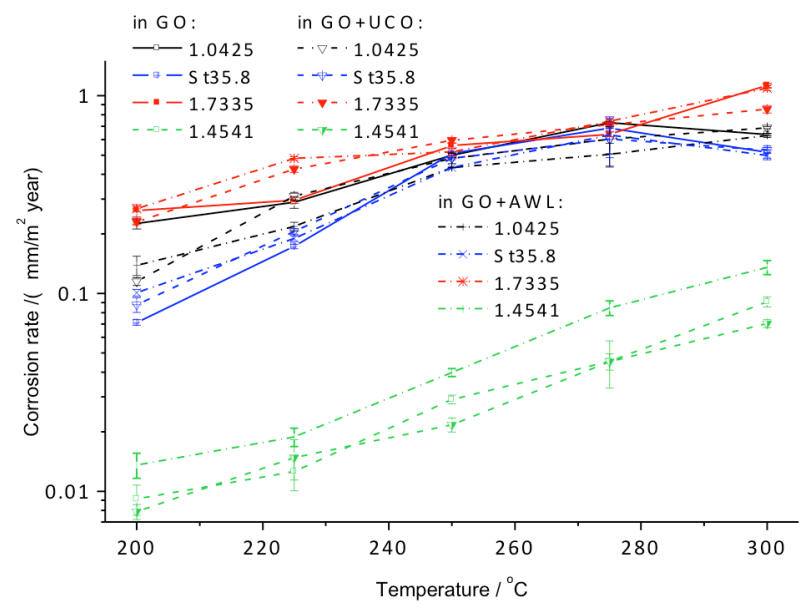

Figure 1. Integral corrosion rates over 504 hours of test period (as a function of temperature) of steel alloys immersed in raw gas oil (GO) and its mixtures with used cooking oil (UCO) and animal waste lard (AWL) at an overall pressure of 90 bar in the presence of $2 \%\left(\mathrm{~m}^{3} / \mathrm{m}^{3}\right)$ hydrogen sulphide, as well as the integral corrosion rates for test periods of 24 hours for the alloys of (b) 1.0425, (c) St35.8, (d) 1.7335, and (e) 1.4541 .

sulphidation rates in all experiments. The higher corrosion resistance of this alloy is well reflected by the almost levelled rates up to $225^{\circ} \mathrm{C}$, although its markedly different behaviour can be observed by the steeply increasing sulphidation rates above $250^{\circ} \mathrm{C}$. This temperature range is associated with the evolution of adherent sulphide scale in appreciable amounts. The special behaviour of this alloy is also underscored by the high sensitivity to composition of the organic phase, i.e. waste lard, showing various corrosion rates even around $200^{\circ} \mathrm{C}$ which remained decisive over the entire temperature range. Corrosion rates were heavily dependent on fluid phase composition with biomass sources mixed in $10 \%(\mathrm{~g} / \mathrm{g})$ than on variation of the temperature up to $250^{\circ} \mathrm{C}$. Generally, sulphidation rates of metals should be similarly more temperature dependent than hydrotreating and desulphurising conversion of the hydrocarbons [25]. In addition, according to the literature, corrosion rates of the $18 / 8$ stainless steels are 10-50 $\mathrm{mm}_{\text {year }}{ }^{-1}$ between 250 and $300^{\circ} \mathrm{C}$ in the presence of hydrogen sulphide at $2 \%$ $\left(\mathrm{m}^{3} / \mathrm{m}^{3}\right)$. In our case, carbon steels indicated much greater sulphidation rates than the advisable as maximum of $0.25 \mathrm{~mm}$ year $^{-1}$, which should be acceptable up to $390^{\circ} \mathrm{C}$ under a pressure of $34 \mathrm{~atm}$ with $10 \%\left(\mathrm{~m}^{3} / \mathrm{m}^{3}\right)$ of hydrogen sulphide [26].

Logarithmic corrosion rates as a function of reciprocal absolute temperature were used to evaluate thermodynamic activation. As results over a short timescale characterise thermodynamics of the sulphide corroding alloys immersed in various organic fluid phases, long-term results are much more dependent on inherent kinetic controls such as barrier effect of the scales. Therefore, reaction rates were both evaluated over the first $24 \mathrm{~h}$ and the entire $504 \mathrm{~h}$ periods. Estimated activation energies are assumed to be closely related to the overall free energy change of the
Table 3. Temperature dependence of logarithmic corrosion rates of steel alloys (in $\mathrm{mol} \mathrm{m}^{2} \mathrm{~s}^{-1}$ ) expressed in activation energies $\left(\Delta E_{\mathrm{a}}^{\#}\right.$ in $\left.\mathrm{kJ} \mathrm{mol}^{-1}\right)$ over the first 24 hours tested at a pressure of $90 \mathrm{bar}$ in the presence of $2 \%\left(\mathrm{~m}^{3} / \mathrm{m}^{3}\right)$ hydrogen sulphide.

\begin{tabular}{cccc}
\hline $\begin{array}{c}\text { Steel alloys } \\
\text { in organic fluids }\end{array}$ & $\begin{array}{c}\text { raw GO } \\
\Delta E_{\mathrm{a}}^{\#}\end{array}$ & $\begin{array}{c}\text { GO-UCO } \\
\Delta E_{\mathrm{a}}^{\#}\end{array}$ & $\begin{array}{c}\text { GO-WL } \\
\Delta E_{\mathrm{a}}^{\#}\end{array}$ \\
\hline 1.0425 & 50.3 & 45.8 & 52.0 \\
St35.8 & 45.4 & 53.3 & 63.1 \\
1.7335 & 35.5 & 31.0 & 45.6 \\
1.4541 & 68.9 & 67.8 & 35.2 \\
\hline
\end{tabular}

Table 4. Temperature dependence of logarithmic integral corrosion rates (in $\mathrm{mm} \mathrm{m}^{-2}$ year $^{-1}$ ) expressed in activation energies $\left(\Delta E_{\mathrm{a}}^{\#}\right.$ in $\left.\mathrm{kJ} \mathrm{mol}^{-1}\right)$ of steel alloys over 21 days. All other parameters are the same as detailed in Table 2.

\begin{tabular}{cccc}
\hline $\begin{array}{c}\text { Steel alloys } \\
\text { in organic fluids }\end{array}$ & $\begin{array}{c}\text { raw GO } \\
\mathrm{a}\end{array}$ & $\begin{array}{c}\text { GO-UCO } \\
\text { GO-WL }\end{array}$ & $\begin{array}{c}\text { GO } \\
\mathrm{a}\end{array}$ \\
\hline 1.0425 & 30.5 & 41.1 & $\Delta E_{\mathrm{a}}^{\#}$ \\
St35.8 & 78.8 & 46.5 & 43.1 \\
1.7335 & 30.3 & 30.3 & 33.3 \\
1.4541 & 30.3 & 41.6 & 53.3 \\
\hline
\end{tabular}

reactions, as presented in Tables 3 and 4. Over a short time period, the highest activation energy of the 1.4541 was ascertained to be in raw gas oil and its mixture with used cooking oil. Nevertheless, about half of the energy was required for the activation in the waste lard mixture of gas oil. This tendency was found to be reversed over long periods when activation was the lowest in gas oil and the highest in the waste lard mixture. This result might only be interpreted as acid corrosion of the 1.4541 taking place over short time periods and sulphidic corrosion occurring over longer periods in parallel with the hydrodesulphurisation gas oil. Adsorption of the fluid phase components and dissolution of the ionized metals are probably inhibited by the firm and adherent sulphide scales. The 1.0425 and St35.8 carbon steels indicated lower activation energies in the short term almost independent of the composition of the organic fluid phase, although the St35.8 might yield some increase with the presence of biomass sources. Over longer periods, except for the St35.8 in gas oil, lower activation with regards to sulphide corrosion manifested, which leads to the recognition that corrosion of these alloys is primarily governed by the hydrogen sulphide. Furthermore, if activation of the interfacial reactions changes it almost certainly decreases over time, which is anticipated in many metal sulphide forming reactions. The 1.7335 low alloy experienced high reaction rates featuring low thermal activation irrespective of the nature of the organic phase and time exposure. Similarly to carbon steels, activation tends to decrease over time, suggesting a catalysed reaction by the scales of precipitating corrosion products, which were porous, susceptible to spalling and semiconductors. This behaviour reveals an insignificant difference between the rates of sulphidic and acidic corrosion, whereas an inefficient barrier effect of the sulphide scale. In short term experiments, 


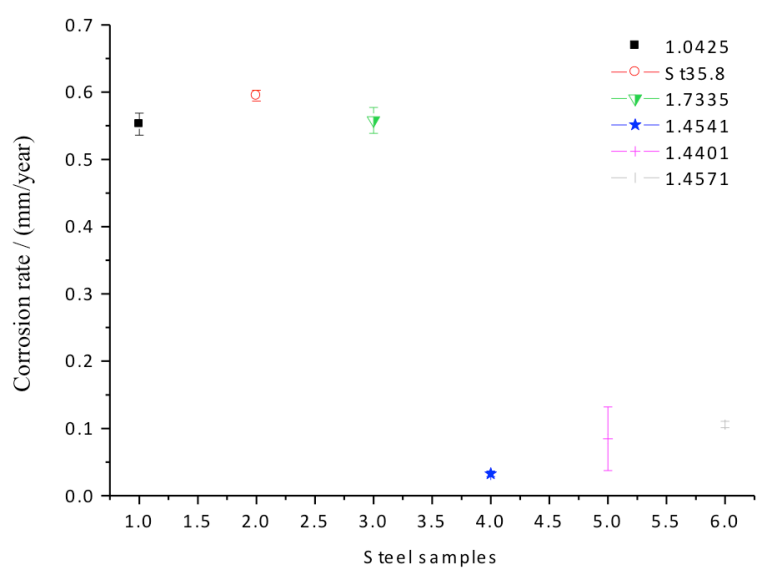

Figure 2. Corrosion rate of steel alloys immersed in refined gas oil tested in a blind experiment for 504 hours at a pressure of 90 bar and temperature of $250^{\circ} \mathrm{C}$ in the presence of $2 \%\left(\mathrm{~m}^{3} / \mathrm{m}^{3}\right)$ hydrogen sulphide.

higher activation energy of the 1.4541 for sulphide corrosion is due to the formation of metal sulphides with the chromium and nickel alloying elements. In contrast, over long time exposures the lower activation energy barrier is partly related to the increased thermodynamic preference in complete balance of the reaction between hydrogen sulphide and iron [27]. Furthermore, the activation of surface processes such as adsorption and dissociation is more attributed to a less preferable free energy balance increasing with the organic materials of used cooking oil and animal fat having a greater absorption abilities. In this regard, the 1.4541 high alloy steel proved to be more sensitive exhibiting more than 2 orders of magnitude changes depending on composition of the organic phase, rather than that of carbon steel alloys indicating changes within a magnitude of 3 times or less. Consequently, the reaction mechanism leading to sulphide corrosion should partly be impacted by adsorption and accelerated by saturated free fatty acids composing a considerable proportion of waste lard. Moreover, the increasing temperature is known to play a vital role in governing the mechanism of naphthenic acid corrosion either by chemical or electrochemical mechanisms [28]. The latter is more dependent on thermal activation as a greater rate of dissociation of the weak acids occurs at elevated temperatures [29]. Electrochemical acceleration may lead to local corrosion and pit formation, whereas chemical naphthenic acid corrosion at lower temperatures results in general processes. Pearlite as an interpenetrating bicrystal phase composed of ferrite and cementite in plain carbon steels is a relatively good cathodic area due to the effective depolarisation for hydrogen ion discharge [23]. In our case, selective corrosion like pitting on specimens of the steel alloys was not observed as a function of temperature between 200 and $300^{\circ} \mathrm{C}$ except for the 1.0425 carbon steel exhibiting pitting corrosion of metal lattice regardless of the organic fluid phase. Process of the latter must be governed by the hydrogen sulphide which with its increasing concentration after a threshold
Table 5. General corrosion rates of steel alloys (in mm year $^{-1}$ ) immersed in raw and refined gas oils, tested at $250^{\circ} \mathrm{C}$ over 21 days under a pressure of 90 bar in the presence of $2 \%\left(\mathrm{~m}^{3} / \mathrm{m}^{3}\right)$ hydrogen sulphide.

\begin{tabular}{ccc}
\hline Steel alloys & Raw gas oil & Refined gas oil \\
\hline 1.0425 & $0.10-0.50$ & 0.55 \\
St35.8 & $0.10-0.50$ & 0.60 \\
1.7335 & $0.30-1.00$ & 0.55 \\
1.4541 & $0.01-0.10$ & 0.05 \\
1.4401 & - & 0.10 \\
1.4571 & - & 0.10 \\
\hline
\end{tabular}

enhances the rate of local process around metal crystal boundaries and sulphide inclusions.

As a blind experiment to probe the effects of an HDS plant using a batch reactor experiment, alloys were tested under the same conditions as for temperature dependence at $250^{\circ} \mathrm{C}$ and the results are presented in Fig. 2 and Table 5. The corrosion rates of carbon steels (1.0425, St35.8 and 1.7335) were greater with low variances of data compared to the ones measured for the 1.4541, 1.4571 and 1.4401 high alloy steels that exhibited reaction rates an order of magnitude lower with high variances, except for the 1.4541. Thus, the firm corrosion resistivity of the 1.4541 alloy was observed, which is primarily connected to its high chromium [30] and moderate nickel contents and the absence of molybdenum. Nickel and molybdenum are of high and moderate concentrations in tested steel alloys causing somewhat decreasing sulphation resistance [31, 32]. Furthermore, from the results of an independent experiment, a less favourable activation of metal sulphide formation is suspected due to the inefficient adsorption and dissociation of hydrogen sulphide from the gas phase besides the absence of dissolved small molecule acids in the fluid phase. Thus, corrosion rates of steel alloys might be the least affected by the adsorption of species from the organic phase only the gaseous phase, such as hydrogen and rather the hydrogen sulphide. The difference between the medium sulphidation resistivity of the 1.4571 and 1.4401 high alloy steels at low temperatures can be explained. On the other hand, by comparing the results of the blind experiment with that obtained in raw gas oil, the corrosion rates were roughly the same or somewhat greater, since the refining of the raw gas oil and the desulphurisation of the raw gas oil content should not have a notable effect on the resistivity of investigated alloys and their observed corrosion rates at least up to $250^{\circ} \mathrm{C}$.

The timespan, over which parabolic corrosion rates appear after a short term linear reaction rate decrease in the induction period is related to development of thick sulphide scales. Therefore, the time dependence of integral corrosion rates is presented in Figs. $3 a-3 d$. The 1.0425 and St35.8 carbon steels indicated parabolic or even more intense decay of corrosion rates over time periods above $250^{\circ} \mathrm{C}$ in all organic fluids but especially in waste lard mixture (Figs.3a and $3 b$ ). The only exception was the $\mathrm{St} 35.8$ at $275^{\circ} \mathrm{C}$ that exhibited a less pronounced decay of sulphidation rates over time. This 
(a)

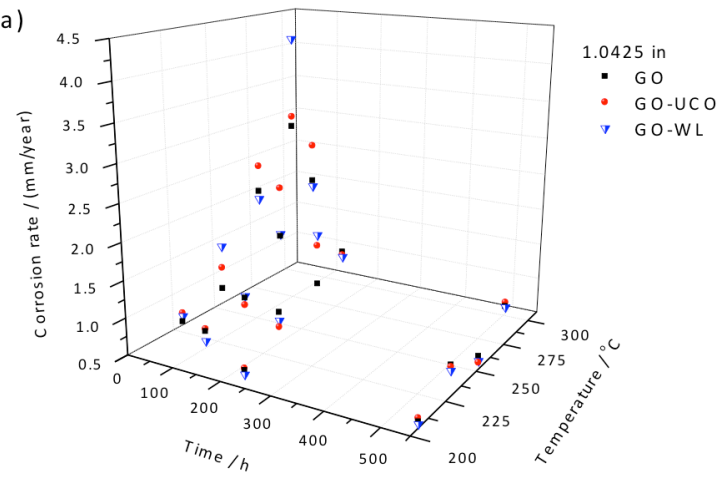

(c)

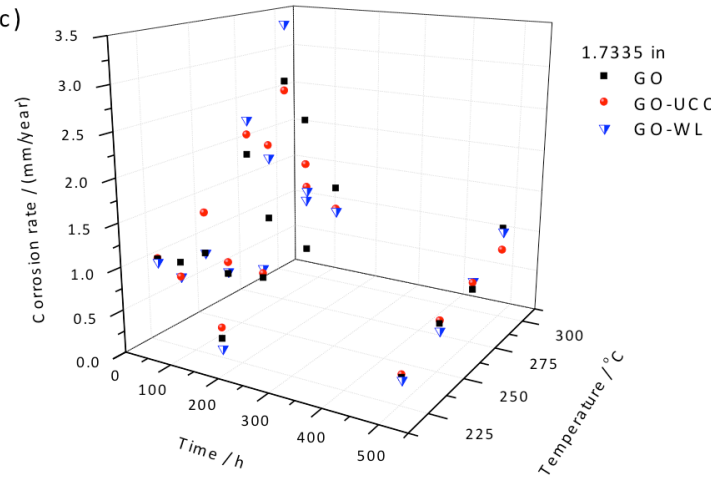

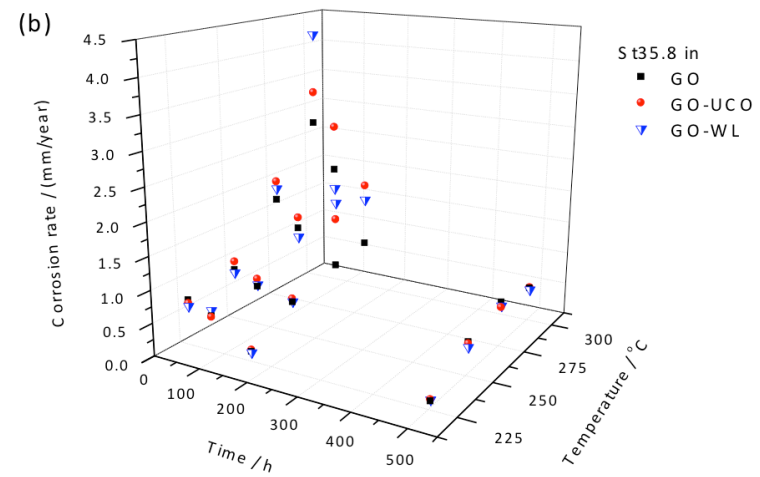

(d)

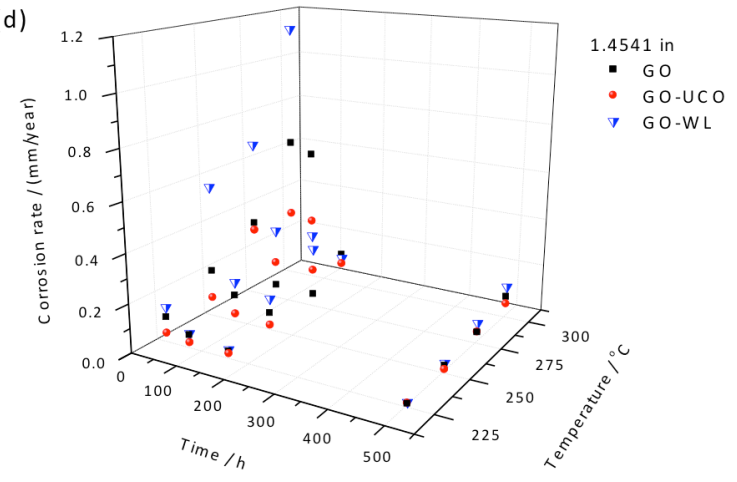

Figure 3. Integral sulphide corrosion rates of steel alloys over time at various temperatures: (a) 1.0425, (b) St35.8(A38), (c) 1.7335 , (d) 1.4541 , parameters as defined in Fig.1.

may be attributed to the partially incorrect experimental data owing to the lack of a large number of samples and parallel experiments to provide a more reliable prediction of the most probable corrosion rates with the least scattering of the mean values as possible. Below $250^{\circ} \mathrm{C}$, a less remarkable decay of reaction rates was ascertained for both metals. The 1.7335 low and 1.4541 high alloys exhibited moderately intense parabolic
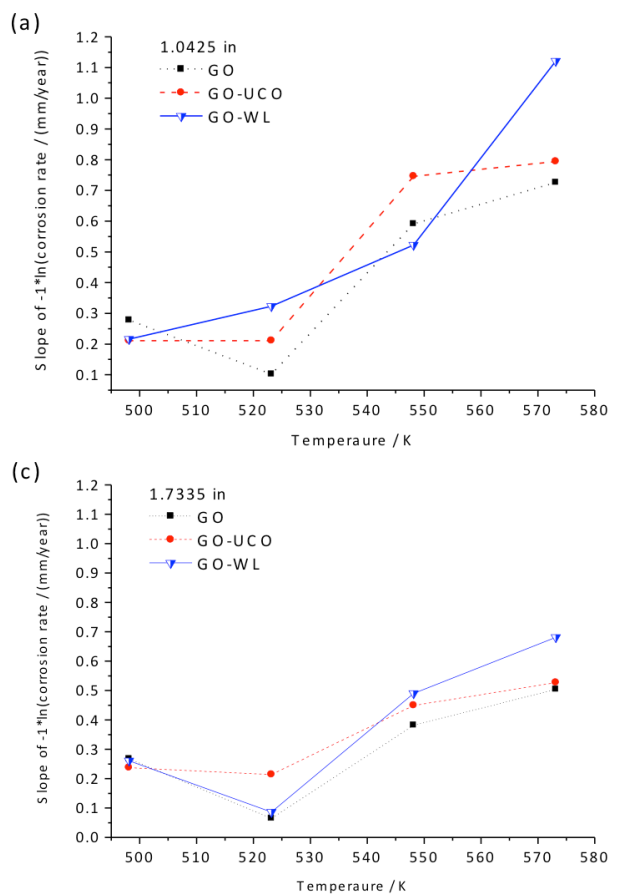
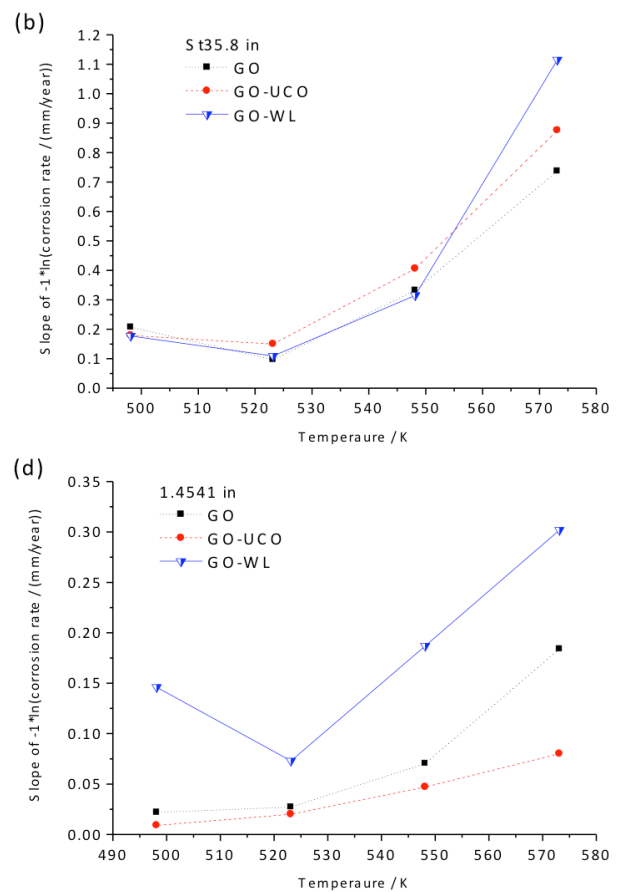

Figure 4. Gradients (in terms of absolute value) of logarithms of integral corrosion rates over 21 days in raw gas oil (GO) and its mixtures with used cooking oil (UCO) and waste lard (WL) as a function of temperature: (a) 1.0425, (b) St35.8, (c) 1.7335 , (d) 1.4541 , parameters as defined in Fig. 1. 
decreases of reaction rates over time. Nevertheless, the gradients of decay of the reaction rates were lower (greater in absolute value) at higher temperatures than quadratic rate decreases at and under $250^{\circ} \mathrm{C}$ as a function of time (Figs. 3 c and 3).

The 1.7335 yielded gave almost constant corrosion rates at $250^{\circ} \mathrm{C}$ between 3 and 21 days of exposure (Fig. 3c). Its induction period seemed to be restrained to the first $24 \mathrm{~h}$ term in the mixture of used cooking oil. The 1.4541 steel experienced the lowest corrosion rates in the used cooking oil mixture over the parameter space (Fig.3d), which exhibited a rather linear dependence as a function of temperature. Overall, all steel alloys indicated the most severe corrosion-type integrity loss in the waste lard mixture of gas oil.

The absolute values of the gradients obtained by linear fitting to the logarithms of the integral corrosion rates measured over 21 days is presented in Figs. $4 a-4 d$. Sulphidation rates of the 1.0425 and St35.8 carbon steels exhibited the highest temperature dependence in the waste lard mixture (a 5 times increase), whereas the lower gradients probably indicate that a less sensitive thermal activation occurs in raw gas oil and the used cooking oil mixture (enhanced by around 3 times, Figs. $4 a$ and $4 b$ ). As for the 1.7335 low and the 1.4541 high alloy steels, the low and the lowest gradients with restrained enhancement of around two times were obtained as a function of temperature (Figs. $4 c$ and $4 d$ ). This signifies a less pivotal role of thermal activation in the interfacial sulphidic corrosion of the latter two alloys but in all cases waste lard was the fluid phase that was proven to be the most susceptible to open thermally-allowed reaction mechanism leading in some cases to the highest corrosion rates by far. Among all steels, only the 1.4541 exhibited low thermal rate dependence in used cooking oil compared to the results obtained in other phases. As a general impression, either the most intense dependence of thermal activation on sulphidation or the highest magnitudes of reaction rates occurred in the waste lard mixture of gas oil. Thus, not only sulphidation takes place by the hydrogen sulphide, but also acidic corrosion occurs and competes with the former at a rate of the latter becoming higher by increasing temperatures. This finding may also point out that the contributing role of free fatty acids in parts of the corrosion processes could be adsorption of mercapto compounds assisted by possible chelating effect and thermally favoured dissociation of the anchoring functional groups. The greater oxidation ability of the organic compounds than hydrogen sulphide, and their more positive redox potentials are due to their stronger electron withdrawing ability boosted by conjugated electron systems of various extents. The desorption of corrosion products is promoted by the proper dissolution of metal ions with lipophilic complexes, and diffusion through porous, cracked or spalled scales, allowing a less hindered access of the steel surface to the species taking part in subsequent processes. In the case of the exclusive hydrogen sulphide corrosion, effective desorption and diffusion from the surface can only be realised by high porosity, cracking or spalling,
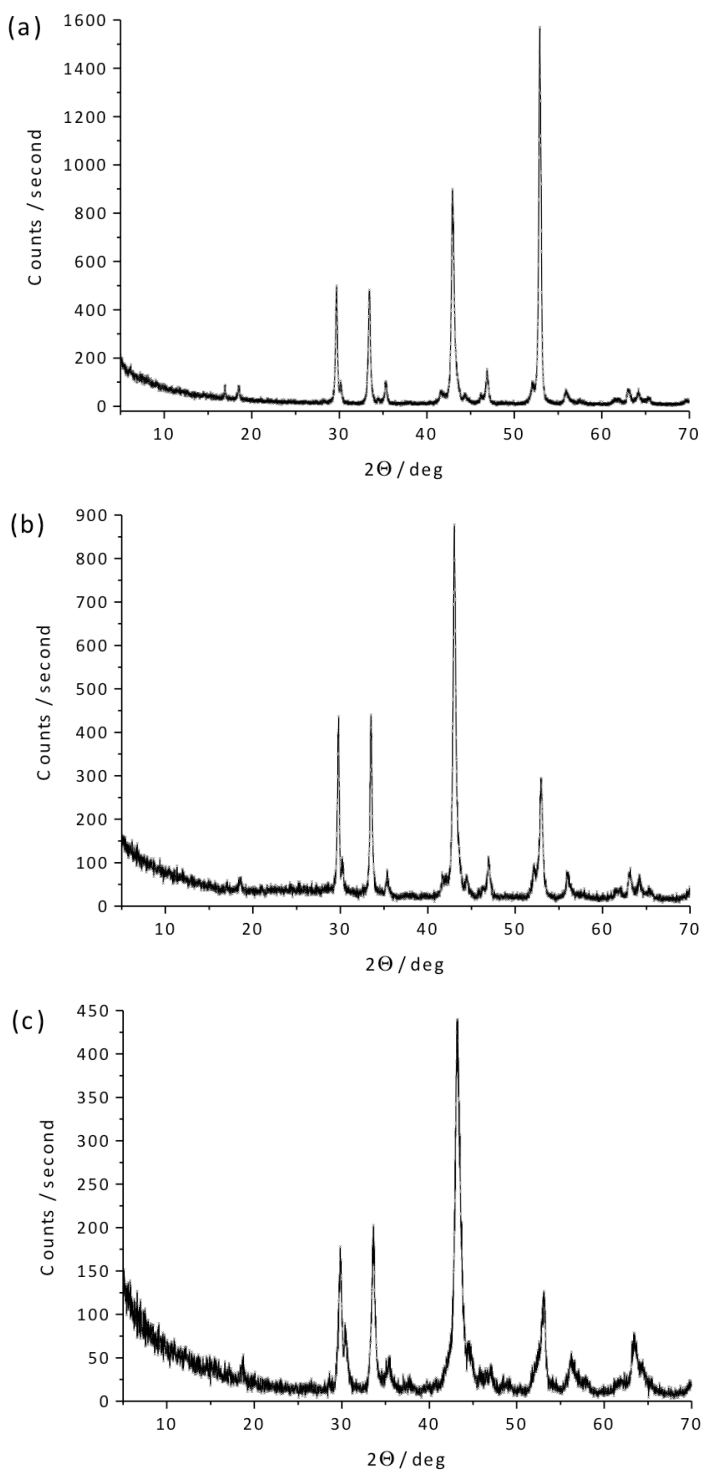

Figure 5. XRD patterns of the (a) 1.0425 carbon steel immersed in raw gas oil and (b) refined gas oil tested at $250^{\circ} \mathrm{C}$, (c) 1.7335 low alloy steel immersed in a gas oil mixture with waste lard $(10 \% \mathrm{~g} / \mathrm{g})$ tested at $300^{\circ} \mathrm{C}$, all for 21 days at a pressure of 90 bar.

and failure of the scales as observed with many of the carbon and low alloy steels but it should not happen to high alloy steels developing quasi-passivating, coherent and adherent sulphide scales. In the latter case, fluid phases with improved wettability based on the closer surface energy of the solid phases and tension of the fluid phases compared to that of the raw gas oil and steel combination is beneficial as less hindered interfacial reactions result.

\subsection{X-ray Diffraction}

In Fig.5a, diffraction pattern of troilite, a 1:1 stoichiometric ratio of iron sulphide (FeS) was identified on the whole in the powder of the spalled scales of the 1.0425 steel tested in raw gas oil at $250^{\circ} \mathrm{C}$. Low crystallinity metallic iron $\mathrm{Fe}(0)$ with high magnetic susceptibility formed the majority of the rest phase. 

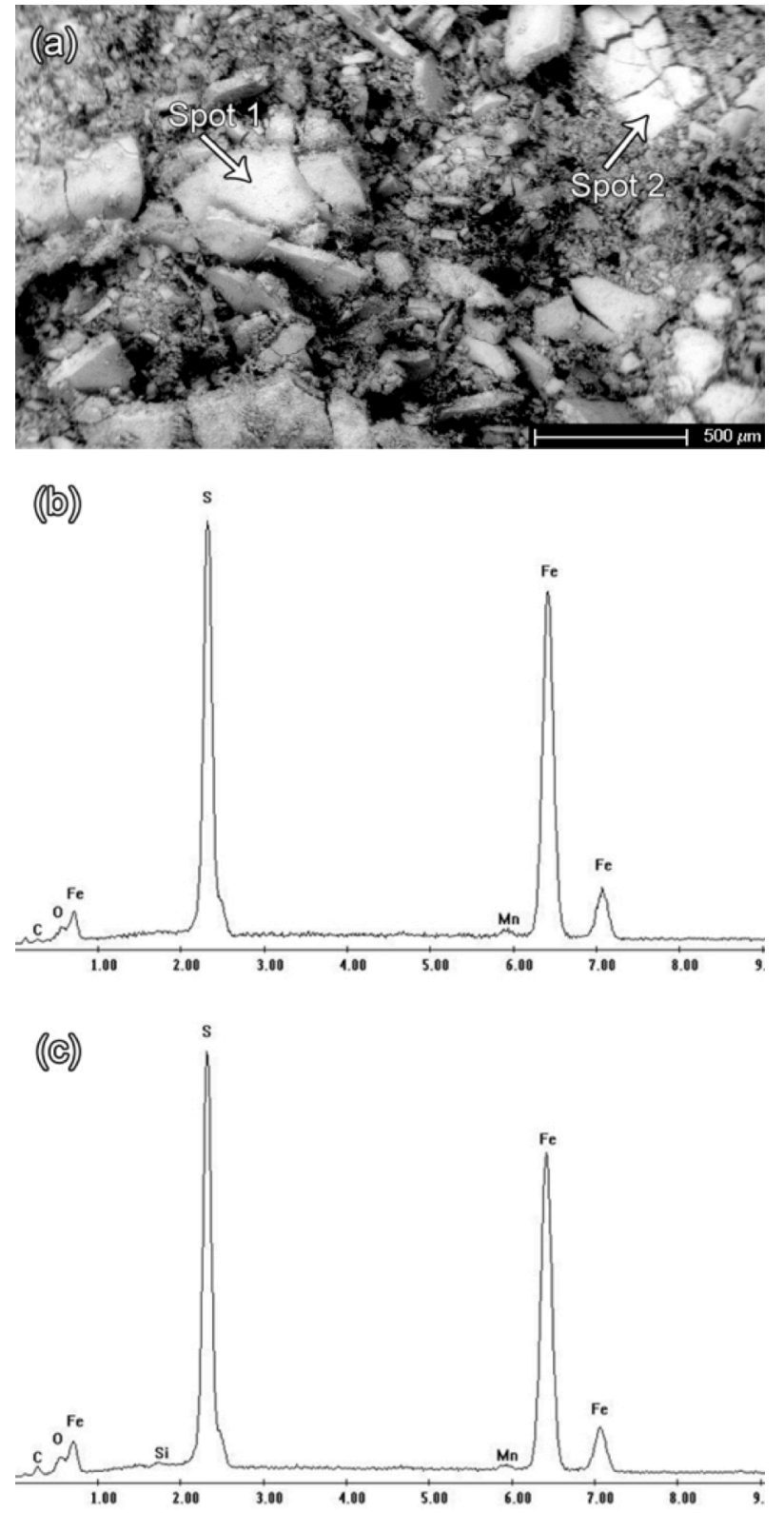

Figure 6. SEM image of (a) the powdered form of sulphide scale removed from the surface of the 1.0425 carbon steel coupons immersed in raw gas oil and tested at a temperature of $250^{\circ} \mathrm{C}$ and pressure of 90 bar; ( $b$ and c) the elemental composition of the scale removed from surface of the coupons obtained by EDS analysis of Spots 1 and 2 marked by arrows, respectively.

Because typical high intensity reflections at $2 \theta$ values of $12^{\circ}, 15^{\circ}$, and $19^{\circ}[33]$ and $40^{\circ}, 50^{\circ}$, and $59^{\circ}$ [34] were not measured, the low intensity reflections gained at $2 \theta$ values of $17.5^{\circ}$ and $30^{\circ}$ might not be connected to mackinawite. The absence of its phase in metal sulphides in the long-term tested samples is attributed to its formation during the early reaction phase and rapid transformation to more stable pyrrhotite, the sub-phase of troilite. The reflections together at $2 \theta$ values of $30^{\circ}$ and $53^{\circ}$ may not be related to greigite as its stability region is above the $\mathrm{H}^{+} / \mathrm{H}_{2}$ equilibrium line. Troilite is more stable in weakly acidic aqueous solutions under
Table 6. SEM-EDS composition (in atomic \%) of the corrosion product of sulphide corrosion scales removed from the surface of carbon steel coupons (1.0425) immersed in raw gas oil tested at a temperature of $250^{\circ} \mathrm{C}$ and pressure of 90 bar.

\begin{tabular}{lrr}
\hline Elements & \multicolumn{1}{c}{ Spot 1 } & \multicolumn{1}{c}{ Spot 2 } \\
\hline $\mathrm{C}(\mathrm{K})$ & 0.00 & 6.95 \\
$\mathrm{O}(\mathrm{K})$ & 6.02 & 7.42 \\
$\mathrm{Si}(\mathrm{K})$ & 0.00 & 0.38 \\
$\mathrm{~S}(\mathrm{~K})$ & 36.58 & 35.77 \\
$\mathrm{Mn}(\mathrm{K})$ & 1.06 & 1.02 \\
$\mathrm{Fe}(\mathrm{K})$ & 56.33 & 48.00 \\
\hline
\end{tabular}

reducing conditions, i.e. below the $\mathrm{H}^{+} / \mathrm{H}_{2}$ equilibrium line [35]. The intense reflection at $2 \theta$ value of $44^{\circ}$ cannot unanimously be attributed to Pyrrhotite [36], as it undoubtedly overlaps with one of the main reflections of polycrystalline iron [37]. In Fig.7b, a different diffraction pattern of the corrosion scale can be identified by the varied intensity ratios of reflections at $43^{\circ}$ and $53^{\circ}$. This is due to a composition change of the scale leading to metallic iron $\mathrm{Fe}^{0}$ and crystalline troilite formation (FeS) in molar ratio of about a 2:1. Thus, a considerable amount of metallic iron segregated over the course of high rates of sulphide corrosion, but its amorphous phase did not result in its conversion to sulphide by either hydrogen sulphide or naphthenic acids in refined gas oil subjected to testing over 21 days at $250^{\circ} \mathrm{C}$ and 90 bar. As expected, long-term medium temperature exposure resulted in high sulphide conversion of metallic iron and the formation of iron sulphide crystals in raw gas oil of a high sulphur content. On the other hand, roughly the same reaction rates resulted in the evolution of a similar amount of sulphide scales in refined gas oil, which proved to be more brittle. Thus, high proportions of the scale detached and rapid disintegration of the metallic phase occurred, resulting in corrosion products with far lower ratio of the elements than stoichiometry. The lower sulphur content of the refined (hydrodesulphurised) gas oil is accountable for this finding because of the lower plasticity of the more compact sulphide scale. An XRD investigation of the sulphide scale formed on the 1.7335 low alloy steel coupons yielded a similar diffraction pattern (Fig.5c) to that of the 1.0425 carbon steel (Fig. $5 b$ ) tested under the same conditions. Nevertheless, in this case the massive amount of highly porous corrosion scale formed with a low spalling ability (high coherence and adherence) should mean less frequent occasions of the surface to renew by spalling or detachment resulting in further hydrogen sulphide attack but lower diffusion hindrance to accessing the metallic surface by sulphide species.

\subsection{SEM and EDX Analyses}

Morphology of the sulphide scales gathered from the bottom of the glass tubes and removed from the surface of the 1.0425 carbon steel specimens is presented in 
Fig.6a. The multiple layers of sulphide scale were moderately easy to detach, brittle, and highly porous. Spalled and detached scales were of a lateral size of about $500 \mu \mathrm{m}$ and a thickness of $40 \mu \mathrm{m}$. The spots of 1 and 2 (arrowed in the image) were analysed to identify the elemental composition of the scale and the SEMEDS results (Figs.6b and 6c) is presented in Table 6. The molar ratios of the iron sulphide (surmised to be $1: 1$ stoichiometric ratio of $\mathrm{FeS})$ and metallic iron $\left(\mathrm{Fe}^{0}\right)$ were 3:1 and 1.8:1 at Spots 1 and 2, respectively. This is in acceptable agreement with and supplementary to XRD results.

\subsection{Micro-Raman Spectroscopy}

The Raman spectra of the sulphide scales gathered from the surface of the steel coupons (tested at $250^{\circ} \mathrm{C}$ over various time exposures) are presented in Fig. 7. Similar spectra were obtained for the St35.8 carbon (b) and 1.7335 low alloy (c) steels. The 1.4541 high alloy steel (d) indicated a strong feature in the wavenumber region of $550-800 \mathrm{~cm}^{-1}$. In the low wavenumber range, a similar Raman spectrum was detected to that of the 1.0425 carbon steel (a). Because Raman spectra depend strongly on the intensity and wavelength of the incident beam, based on the weak feature of the spectra around the main Raman characteristic wavenumbers, it is thought that small proportion of troilite in the crystalline phase [38] should probably have formed after the chemical conversion of the initial metal sulphide on the St35.8 and 1.7335 (lines at 289 and $290 \mathrm{~cm}^{-1}$ ) over a short time period. Metal sulphides, detected in a somewhat greater proportion of crystallinity (yielding a relatively low amount of scale) formed on the slower corroding 1.4541 , resulting in to the more pronounced features in the wavenumbers between 550 and 800 $\mathrm{cm}^{-1}$. Corrosion scales of St35.8, 1.7335, and 1.4541 alloys yielded intense broad and weak features at 1292 and $218 \mathrm{~cm}^{-1}$ as a result of the troilite phase. These characteristic wavenumbers were only found in the spectra in accordance with the literature [40]. This reveals that the low crystallinity of corrosion scales evolved within 24 hours. Other Raman features of troilite, a weak intensity peak at $456 \mathrm{~cm}^{-1}$ and the sharp ones at 600,398 , and $283 \mathrm{~cm}^{-1}$ [41], and 400 and 295 $\mathrm{cm}^{-1}$ [38] were not found. On the other hand, iron sulphide in a form close to mackinawite [42] might keep evolving in the early stages on 1.0425 , St35.8 and 1.4541 as wavenumbers of moderate intensity at 321 , 317 , and $315 \mathrm{~cm}^{-1}$, respectively, were detected. They usually appear as intense overlapping peaks between 310 and $320 \mathrm{~cm}^{-1}$ depending on the degree of crystallinity [43]. Thus, this seems to concur with greater reaction rates leading to a lower proportion of crystallinity in the product as the rate of nucleation overtakes to a level of far beyond orientation and growth. Insignificant Raman intensities in the regions of $280-360 \mathrm{~cm}^{-1}$ (at 206, 257, and $296 \mathrm{~cm}^{-1}$ and at 256, 312 , and $\left.355 \mathrm{~cm}^{-1}\right)$ are generally connected to mackinawite ( $\mathrm{Fe}(\mathrm{II}) \mathrm{S}_{1-\mathrm{x}}$ and $\mathrm{Fe}(\mathrm{II})-\mathrm{Fe}(\mathrm{III}) \mathrm{S}_{1-\mathrm{x}}$ ) and ironrich mackinawite, and greigite, respectively [44]. In the

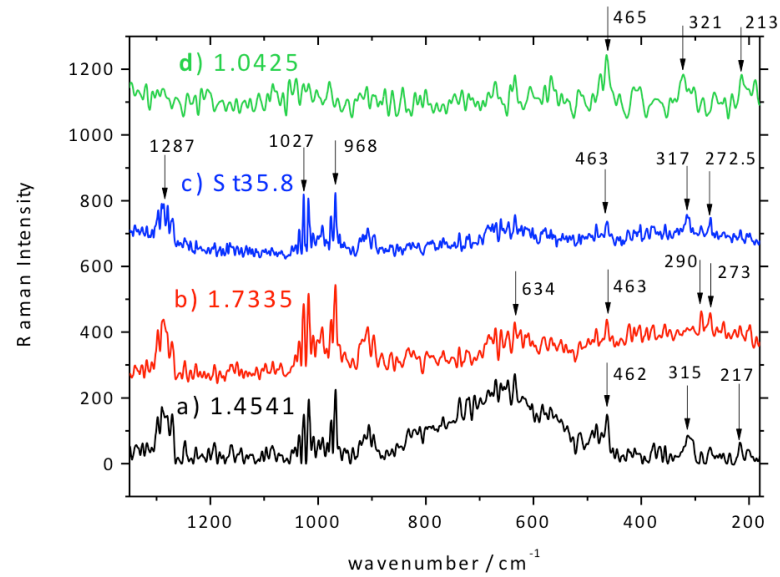

Figure 7. Micro-Raman survey spectra of steel alloys tested under specified conditions as stated: a) 1.0425 $\left.\left(250^{\circ} \mathrm{C} / 20 \mathrm{bar}, 8 \mathrm{~h}\right), \mathrm{b}\right)$ St. $\left.35.8\left(250^{\circ} \mathrm{C} / 50 \mathrm{bar}, 24 \mathrm{~h}\right), \mathrm{c}\right)$ $1.7335\left(250^{\circ} \mathrm{C} / 20\right.$ bar, $\left.8 \mathrm{~h}\right)$ and d) $1.4541\left(250^{\circ} \mathrm{C} / 50\right.$ bar, $24 \mathrm{~h})$.

1.4541, the very low Raman intensity at $240 \mathrm{~cm}^{-1}$ is probably due to the presence of chromium-rich troilite whereas the low intensity features at 255 (290) and 365 $\mathrm{cm}^{-1}$ are partly connected to daubrelite $\left(\mathrm{FeCr}_{2} \mathrm{~S}_{4}\right.$ and $\mathrm{FeCr}_{2} \mathrm{~S}_{3}$ ). Nonetheless, these phases should have been present in negligible quantity, because none of the supporting XRD results could confirm the presence of such crystals, besides theoretical thermodynamic calculations of stable regions of iron sulphides (see discussion). In all cases, the low crystallinity of the corrosion products is attributed to the short time-scales and low temperatures of the experiments. It should also be noted that amorphous iron sulphide scales, which evolved in the induction periods were far less coherent, more crystalline, and more susceptible to spalling and detaching than the ones formed in slower reactions. Thus to explain this phenomenon, lower mechanical stress might have accumulated over time in scales generated by slower and decreasing rates of reactions. As a result, the induction time of sulphide scale formation should be very low at a pressure as low as 20 bar but crystallisation must occur over longer periods. Therefore, time constants in terms of spalling, and the failure of the scales to detach might be related to relaxation of accumulated stresses, probably at a rate faster than the crystallisation of iron sulphides. For troilite, it must be longer than 8 hours, but much less than 21 days at $250^{\circ} \mathrm{C}$ and a pressure of 90 bar. In fact [45], due to kinetic reasons in connection with the highest reaction rate of scale growing without diffusiontype mass transport control [46], it has been stated that [47] generally mackinawite is expected to form rapidly first almost regardless of reaction conditions. For thermodynamic reasons, if metastable cubic $\mathrm{FeS}$ formed, it should have also transformed into pyrrhotite and troilite over the weeks the experiment was undertaken at a moderate temperature and pressure both in the presence [48] and absence of chloride [49]. Phase transformation of metal sulphides to Troilite takes place in days or even hours as was found in our case. The evolution of pyrrhotite might occur over a couple of 
days so its detection in samples tested over at least 3 days can be anticipated. Not exactly in line with the location of the pyrrhotite-troilite transition boundary $[50,51]$, in our case elevated temperatures favoured the formation of troilite rather than pyrrhotite under less than 2 bar of partial pressure of the hydrogen sulphide.

\section{Discussion}

The hypothetical growth in thickness of the sulphide scales over selected time periods based on the mass changes of the coupons is given in Figs. $8 a-8 d$. The 1.0425 at $225^{\circ} \mathrm{C}$ exhibited thicker scale development in biomass mixtures with lower reductions in rate over time than in neat gas oil (Fig. $8 a$ ). At $250^{\circ} \mathrm{C}$, all corrosion rates exhibit proportional growth as time of exposure increases. Such linear rates of sulphidation started to decelerate as a function of time above $250^{\circ} \mathrm{C}$. The lowest variation of corrosion rates over time manifested in the used cooking oil mixture. The St35.8 exhibited similar sulphidation resistance behaviour up to $275^{\circ} \mathrm{C}$ but at $300^{\circ} \mathrm{C}$ a higher drop in corrosion rates was observed in mixed organic environment of the biomass and a smaller reduction in neat gas oil over time (Fig.8b). The 1.7335 experienced increasing corrosion rates in all fluids as a function of temperature, without any notable decrease related to barrier effects over longer time periods (Fig.9c). Depending on the type of the organic phase, moderate drops and increases in the corrosion rates over intermittent periods were observed at 74,168 , and $168 \mathrm{~h}$ for $1.0425, \mathrm{St} 35.8$ and 1.7335 steels, respectively. According to our experience, the growth rate in the thickness of stable scales on carbon steels never exceeded $10 \mu \mathrm{m}$ over the first 3 days. Up to $250^{\circ} \mathrm{C}$, the 1.0425 exhibited a higher and the St35.8 a somewhat lower susceptibility of the sulphide layers to spalling and detachment. The 1.7335 manifested the development of more coherent scales that were not susceptible to spalling or failure over time especially at and above $275^{\circ} \mathrm{C}$. A less frequent variation in time of reaction rates along with the observed quantity of detached scales in the form of a sediment at the bottom of the glass tubes led to the conclusion that the about low compactness, and high porosity of the sulphide scales are the primary reasons for the longlasting high sulphidation rate of this alloy. Nonprotective scales exhibit linear growth and a mass change over time similar to that of the 1.733. This is typical for porous or cracked films, which facilitate the less hindered transport of reactants and access to the metallic phase at faster rates than at which the chemical reaction proceeds. As far as the 1.0425 and St35.8 carbon steels are concerned, due to the high barrier nature of the sulphide scales at elevated temperatures, variations in the time needed to renew the surface almost to the metallic phase were necessary to maintain the high reaction rates over long periods of time. Scale failures should have been caused by the accumulation of high internal stresses along with high growth rates taking place on polycrystalline surfaces. Such failures
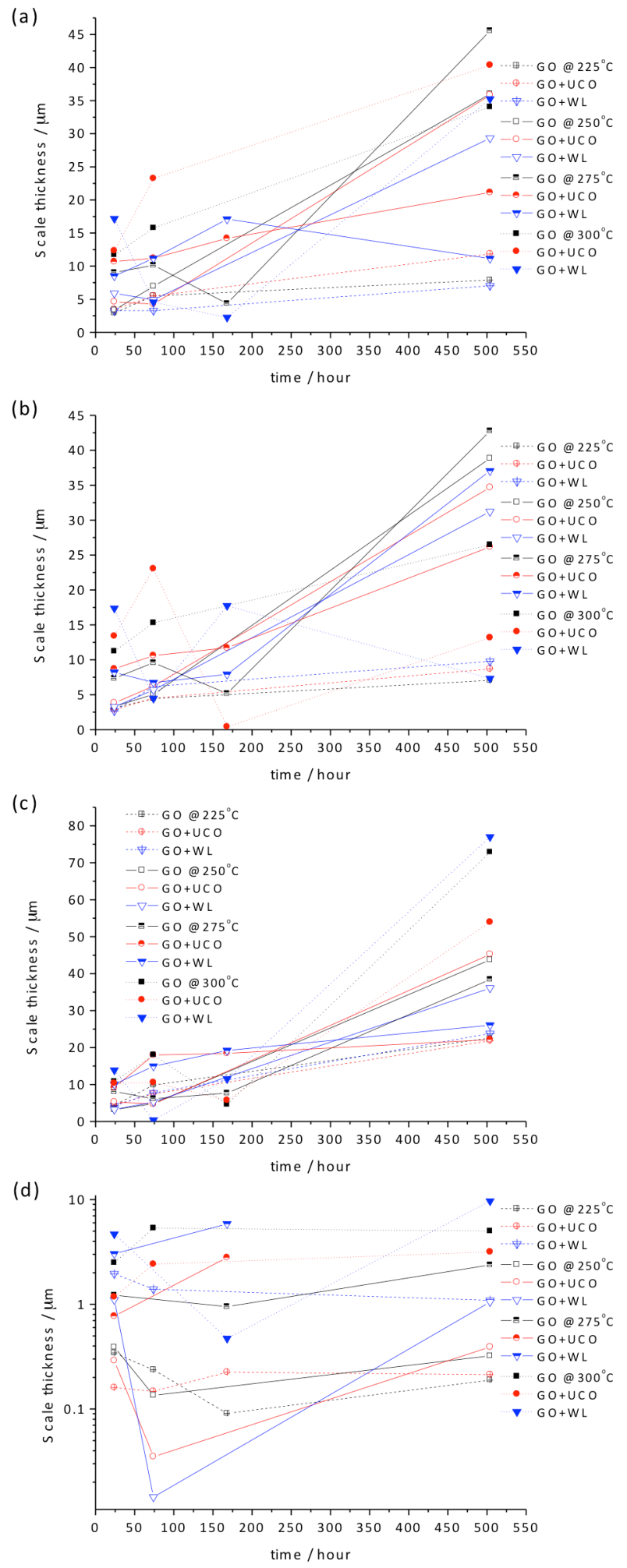

Figure 8. Hypothetical differential metal-sulphide scale thicknesses developed over time periods based on the mass change of the coupons of steel alloys immersed in refined gas oil (GO) and its mixtures with used cooking oil (UCO) or waste lard (WL) tested at a pressure of 90 bar in the presence of $2 \%\left(\mathrm{~m}^{3} / \mathrm{m}^{3}\right)$ hydrogen sulphide.

do not occur within scales at the scale/metal interface since it is cohesive in nature due to the high electrostatic forces that exceed the yield strength of the scales [52]. 
Thus, hypothetically speaking, further scale growth as a solid-state reaction must trigger the breakdown of scales [53]. This is basically in line with the literature [54] as the corrosion resistances of carbon and low alloy steels are approximately equal. The low chromium alloys of up to $5 \%(\mathrm{~g} / \mathrm{g})$ warrant little or no advantages over carbon steels in terms of resistance to reactions with hydrogen sulphide. Nonetheless, the $18 \mathrm{Cr}-8 \mathrm{Ni}$ stainless steels feature acceptable resistances over a wide range of pressures, temperatures, and hydrogen sulphide concentrations, except under severe conditions [55].

In other aspects, the protection potential of sulphide scales for carbon steels is usually questionable when well adsorbing species or compounds are in fluid media. After the first phase of mackinawite growth, corrosion rates can accelerate because the tarnish is not a uniform film, but rather composed of discrete crystallites that are highly permeable [56]. If the electrochemical mechanism of sulphide corrosion occurs and cathodic depolarisation is efficient, pyrrhotite formation becomes anodically controlled by cation diffusion that takes place through sulphides, which are in part limited by maximum reaction rates. Thus, as thermodynamic simulations delineated the region of stability of troilite [57], in our experiment the electrode potential of the steel coupons should have been between -0.4 and $-0.65 \mathrm{~V}$ versus standard hydrogen electrode (SHE), which is a narrow stability region in neutral media. At $250^{\circ} \mathrm{C}$, the 1.4541 showed slight variations in sulphidation over time regardless of the fluid phase (Fig.8d). The scale structure was less compact and easily removable from the surface. At $250^{\circ} \mathrm{C}$, the highest decrease in reaction rate was obverserved over moderate periods of time that could only be accounted for by the greater initial sulphidation rates, increased compactness, and packing of the corrosion film, resulting in the metallic surface becoming more rapidly blocked, thus preventing subsequent reactions leading to less hindered ionic diffusion. As the temperature increased to $275^{\circ} \mathrm{C}$ and above, time variations in the reaction rates became less remarkable as a function of time with similar changes in all organic fluids. This may suggested as the factors of utmost importace that determines the type of sulphide scales that could grow on the specimens, which slows down further metal sulphide forming reactions. As recognised first by Wagner [58], some metals develop oxide scales exhibiting excellent protection characteristics as a result of the decreasing diffusion rate of ions through compact scales. Such quasi-passivating behaviour was found in the sulphide corrosion of the 1.4541 under the experimental conditions, as mass changes obeyed the parabolic law as a function of time. This is in accordance with the nature of chromium, which is considered to be present in relatively high amounts as the most significant alloying element that increases sulphidation resistance. In some instances, the logarithmic rate of sulphide conversion by mass change was also observed in the initial phases of the reactions. The induction periods in the formation of metal sulphides were intense probably because of the lack of mass transport hindrances at the interfaces which evidently evolved to various extents in later phases of the experiments as thermal activation between 200 and $300^{\circ} \mathrm{C}$ is inefficient to maintain high ion fluxes through the lattice of scales of moderate thicknesses and compactnesses. Thermodynamic calculations based on Gibbs free energy changes of the reactions of sulphide corrosion processes do not justify remarkable changes in reaction rates as a function of temperature. Therefore, kinetic factors are likely to play a pivotal role in the enhancement of reaction rates in all cases. As a comparison of the protection performances provided by sulphide scales on different sorts of steel alloys, corrosion layers on the 1.4541 and the St35.8 evolved better barrier characteristics at higher temperatures than under $250^{\circ} \mathrm{C}$, which is generally in agreement with the terms of scaling tendency [59]. More coherent and adherent scales of metal sulphides formed at greater rates as corrosion products were not as solubile in GO and UCO compared to the WL mixture. So precipitates shrank and became more compact, which is partly is accounted to their mediocre thermal activations. In waste lard mixtures, corrosion through both chemical and electrochemical mechanisms assisting each other resulted in a pronounced efficiency of thermal activation was experienced along with the impact of acids relegating protective function of the chromium-, nickel-, and molybdenum-alloying elements. Aside from the 1.7335 exhibiting good mechanical protection characteristics independent of temperature, the 1.0425 yielded rapidly increasing sulphidic corrosion with temperature. The former is attributed to high porosity of the sulphide film and the latter is explained by detachment of the layers thereof regularity depends on the corrosion rate and surface structure, orientation of the metallic crystallites, affecting the rate of stress accumulation in the corrosion products. The pronounced sensitivity of corrosion resistance in the 1.4541 regarding composition of the organic fluid phase resulted in high reaction rates especially in waste lard mixtures not only in the short run, but over longer periods, suggests the existence of an altered microstructure, lower compactness and increased solubility of metals and sulphide scales in acid containing fluid than in neat gas oils. This is in agreement with the literature [60] as naphthenic acids are most accountable for the highly corrosive nature oils [61-64]. The high corrosion rate of the St35.8 at low temperatures probably is a result of diffusion along short-circuit paths at grain boundaries or dislocations rather than of lattice diffusion, as thermal activation is high compared to over long periods when kinetic control of barrier effects besides the seldom failure of scales. Slow growing scales proved to be more coherent and protective, exerting better mass transport control on during subsequent reactions. The Gibbs free energy change of the metal sulphide reactions is inferior to diffusion activation in the solid state. The growth mechanism of metal sulphide scales takes place via outward diffusion of cations which leads to lower rate of stress accumulation in the layer. In carbon steel 
samples, spalling and scale failure were experienced over the first 24 hours as one of the four types of stressrelief mechanisms. In the case of thin scales, maximumstress affects metal/scale interface. The imperfections of the flat surface and the geometry of the coupons is also partially connected to the detachment of sulphide scales [65] especially at the inner and outer edges as flat interfaces are less susceptible to spalling compared to the ones with small radii, high curvatures [66]. Low film ductility at low temperatures and high corrosion rates might inevitably lead to spalling, undermining and detachment.

\section{Conclusion}

The corrosion rates of carbon steels yielded an almost linear dependence as a function of temperature between 200 and $300^{\circ} \mathrm{C}$ regardless of the biomass fuel sources. Although carbon steels developed less spalling and detaching sulphide scales with increasing temperature, the porous layers did not contribute to the higher protection of the metallic phase as a result of their enhanced barrier natures. In contrast, on the surface of high alloy steels sulphide scales with excellent protection characteristics evolved during the induction period and the layer formation is assisted by temperature.

Integrity loss of the high alloys can severely be affected by biomass fuel sources such as animal waste lard when they are used in high proportions along with raw gas oil. Free fatty acids play probably a dominant role in the corrosion mechanism.

The higher corrosion rates observed than reported in the literature lead us to conclude that the proportion of the biomass sources used, especially those the ones having high free fatty acid contents, should preferably be kept low to prevent rapid losses in integrity of steel alloys, ensuring long and safe life cycles of the equipment used in HDS refining plants.

\section{Acknowledgement}

The authors are indebted to Ferenc Molnár, Corrosion Research Group, Department of Physical Chemistry, Institute of Chemistry, University of Pannonia, for his invaluable discussions and advice on planning experiments and evaluating results. Bence Nagy, MOL Co., is gratefully acknowledged for his mediation and help in the procurement of precursors for the experiments. The authors are indebted to Róbert Bocsi, Department of Chemical Processing, Institute of Chemical and Process Engineering, University of Pannonia, for his instruction, laboratory work and help in detecting and measuring the concentrations of hydrogen sulphide during reactor experiments. The authors are grateful to Csaba Tóth, Department of MOL Hydrocarbon and Coal Processing, Institute of Chemical and Process Engineering, University of Pannonia, for his variety of contributions to the experimental work, and to Margit Balázs for her analytical results of the biomass fuel sources.

\section{REFERENCES}

[1] Knothe, G.: Biodiesel and renewable diesel: A comparison, Prog. Energy Combus. Sci., 2010 36(3), 364-373 DOI: 10.1016/j.pecs.2009.11.004

[2] ASTM D6751-15ce1, Standard Specification for Biodiesel Fuel Blend Stock (B100) for Middle Distillate Fuels (ASTM International, West Conshohocken, PA) 2015 DOI: 10.1520/D6751-15CE01

[3] Standard EN 14214:2008, Automotive fuels - fatty acid methyl esters (FAME) for diesel engines requirements and test methods (European Committee for Standardization, Brussels, Belgium) 2008

[4] Lapuerta, M.; Villajos, M.; Agudelo, J.R.; Boehman, A.L.: Key properties and blending strategies of hydrotreated vegetable oil as biofuel for diesel engines, Fuel Process Technol., 2011 92(12), 2406-2411 DOI: 10.1016/j.fuproc.2011.09.003

[5] Bezergianni, S.; Kalogianni, A.: Hydrocracking of used cooking oil for biofuels production, Bioresource Technol., 2009 100(17), 3927-3932 DOI: 10.1016/j.biortech.2009.03.039

[6] Lappas, A.A.; Bezergianni, S.; Vasalos, I.A.: Production of biofuels via co-processing in conventional refining processes, Catal. Today, 2009 145(1-2), 55-62 DOI: 10.1016/j.cattod.2008.07.001

[7] Choudhary, T.V.; Phillips, C.B.: Renewable fuels via catalytic hydrodeoxygenation, Appl. Catal. A: Gen., $2011 \quad 397(1-2), \quad 1-12 \quad$ DOI: 10.1016/j.apcata.2011.02.025

[8] ASTM D7467-15ce1, Standard Specification for Diesel Fuel Oil, Biodiesel Blend (B6 to B20), (ASTM International, West Conshohocken, PA) 2015 DOI: $10.1520 /$ D7467-15CE01

[9] Standard EN 590:2004. Automotive fuels - diesel requirements and test methods (European Committee for Standardization, Brussels, Belgium) 2009

[10] Bezergianni, S.; Kalogianni, A.; Vasalos, I.A.: Hydrocracking of vacuum gas oil - vegetable oil mixtures for biofuels production, Bioresource Technol., 2009 100(12), 3036-3042 DOI: 10.1016/j.biortech.2009.01.018

[11] Huber, G.W.; O'Connor, P.; Corma, A.: Processing biomass in conventional oil refineries: Production of high quality diesel by hydrotreating vegetable oils in heavy vacuum oil mixtures, Appl. Catal. A: Gen., 2007 329, 120-129 DOI: 10.1016/j.apcata.2007.07.002

[12] Farrauto, R.J.; Bartholomew, C.H.: Fundamentals of industrial catalytic processes (Blackie Academic and Professional, Chapman \& Hall, London, UK) 1997

[13] Mikulec, J.; Cvengros, J.; Joríkov, L.; Banica, M.; Kleinová, A.: Second generation diesel fuel from renewable sources, J. Cleaner Prod., 2010 18(9), 917-926 DOI: 10.1016/j.jclepro.2010.01.018

[14]Hancsók, J.; Baladincz, P.; Kasza, T.; Kovács, S.; Tóth, Cs.; Varga, Z.: Biogas oil production from waste lard, J. Biomed. Biotechnol., 2011 ID 384184, p. 9 DOI: $10.1155 / 2011 / 384184$ 
[15] Craig, W.K.; Soveran, D.W.: Production of hydrocarbons with a relatively high cetane rating (US Patent 4,992,605) 1991

[16]Stumborg, M.; Wong, A.; Hogan, E.: Hydroprocessed vegetable oils for diesel fuel improvements, Bioresource Technol., 1996 56(1), 13-18 DOI: 10.1016/0960-8524(95)00181-6

[17] Monnier, J.; Tourigny, G.; Soveran, D.W.; Wong, A.; Hogan, E.N.; Stumborg, M.: Conversion of biomass feedstock to diesel fuel additive assigned to natural resources (US Patent 5,705,722) 1998

[18]Klass, D.L.: Biomass for renewable energy, fuels and chemicals (in Cleveland, C.J.: Encyclopedia of energy, $1^{\text {st }}$ ed., Elsevier Science Inc., Oxford, UK) 2004 pp. 1-20

[19] Knothe, G.; van Gerpen, J.; Krahl, J.: The Biodiesel Handbook (AOCS Press, Champaign, IL, USA) 2005

[20]Topolnitskij, P.: Corrosion protection of oil production and refinery equipment, Chem. Chem. Technol., 2007 1(1), 45-54

[21] Sari, A.; Kaygusuz, K.: Some fatty acids used for latent heat storage: thermal stability and corrosion of metals with respect to thermal cycling, Renewable Energy, 2003 28(6), 939-948 DOI: 10.1016/S0960-1481(02)00110-6

[22]Qu, D.R.; Zheng, Y.G.; Jing, H.M.; Yao, Z.M.; Ke, W.: High temperature naphthenic acid corrosion and sulphidic corrosion of Q235 and $5 \mathrm{Cr} 1 / 2 \mathrm{Mo}$ steels in synthetic refining media, Corr. Sci., 2006 48(8), 1960-1985 DOI: 10.1016/j.corsci.2005.08.016

[23]NIST Standard Reference Data: Thermophysical properties of fluid systems, webbook.nist.gov/chemistry/fluid/ (last accessed 21-08-2016)

[24]Bezergianni, S.; Dimitriadis, A.: Temperature effect on co-hydroprocessing of heavy gas oil waste cooking oil mixtures for hybrid diesel production, Fuel, 2013 103, 579-584 DOI: 10.1016/j.fuel.2012.08.006

[25] Sedriks, A.J.: The corrosion monograph series: Corrosion of stainless steels $\left(2^{\text {nd }}\right.$ Ed., Verlag John Wiley \& Sons, Chichester, UK) 1979

[26] John, R.C.: Compilation and use of corrosion data for alloys in various high-temperature gases, Nace Int., 1999 Corrosion Paper no. 99073

[27]Barin, I.I.: Thermochemical data of pure substances (VCH Verlag, Weinheim, Germany) 2008 DOI: 10.1002/9783527619825

[28] Slavcheva, E.; Shone, B.; Turnbull, A.: Review of naphthenic acid corrosion in oil refining, Br. Corr. $\begin{array}{llll}J ., & 1999 & \mathbf{3 4}(2), & 125-131\end{array}$ 10.1179/000705999101500761

[29]Wu, X.Q.; Jing, H.M.; Zheng, Y.G.; Yao, Z.M.; Ke, W.: Resistance of Mo-bearing stainless steels and Mo-bearing stainless-steel coating to naphthenic acid corrosion and erosion-corrosion Corr. Sci, 2004 46(4), 1013-1032 DOI: $10.1016 / \mathrm{S} 0010-938 \mathrm{X}(03) 00192-6$
[30] Coutsouradis, D.; Davin, A.: The sulphidation of cobalt and cobalt alloys by sulphur vapour and hydrogen sulphide (in Ed.: Foroulis, Z.A.; High temperature metallic corrosion of sulfur and its compounds, Electrochemical Society, New York, USA) 1970 pp. 235-254

[31]Davin, A.; Coutsouradis, D.: What are the effects of alloying elements simply or in combination on hot corrosion in high temperature corrosion of aerospace alloys, AGARD Conf. Proc., 1973 120, 221-234

[32] Davin, A.; Coutsouradis, D.; Habraken, L.: Influence of alloying elements on the hot-corrosion resistance of Co-Cr alloys, Mat. Corr., 1971 22(6), 517-527 DOI: 10.1002/maco.19710220609

[33] Lennie, A.R.; Redfern, S.A.T.; Schofield, P.F.; Vaughan, D.J.: Synthesis and Rietveld crystal structure refinement of mackinawite, tetragonal FeS, Mineral. Mag., 1995 59(4), 677-683 DOI: 10.1180/minmag.1995.059.397.10

[34]Jeong, H.Y.; Lee, J.H.; Hayes, K.F.: Characterization of synthetic nanocrystalline mackinawite: crystal structure, particle size, and specific surface area, Geochim. Cosmochim. Acta, 2008 72(2), 493-505 DOI: 10.1016/j.gca.2007.11.008

[35] Schoonen, M.A.A.; Barnes, H.L.: Reactions forming pyrite and marcasite from solution: I. Nucleation of $\mathrm{FeS}_{2}$ below $100^{\circ} \mathrm{C}$, Geochim. Cosmochim. Acta, 1991 55(6), 1495-1504 DOI: 10.1016/0016-7037(91)90122-L

[36] Csákberényi-Malasics, D.; Rodriguez-Blanco, J.D.; Kovács Kis, V.; Rečnik, B.; Aleksander L.G.; Pósfai, M.: Structural properties and transformations of precipitated FeS, Chem. Geol., 2012 294-295, 249-258 DOI: 10.1016/j.chemgeo.2011.12.009

[37] Saw, C.K.; Lian, T.; Day, S.D.; Farmer, J.C.: X-ray diffraction techniques for structural determination of amorphous materials, Report No, UCRL-TR225388, INIS Repository, 2006 38(24), 1-30 DOI: $10.2172 / 900132$

[38] Wang, H.; Salveson, I.: A review on the mineral chemistry of the non-stoichiometric iron sulphide, $\mathrm{Fe}_{(1-\mathrm{x})} \mathrm{S} \quad(0 \leq \mathrm{x} \leq 0.125)$ : polymorphs, phase relations and transitions, electronic and magnetic structures, Phase Transit., 2005 78, 547-567 DOI: 10.1080/01411590500185542

[39] Keller-Besrest, F.; Collin, G.: Structural aspects of the $\alpha$ transition in stoichiometric $\mathrm{FeS}$ : identification of the high-temperature phase, $J$. Solid State Chem., $1990 \mathbf{8 4}, 194-210$ DOI: 10.1016/0022-4596(90)90319-S

[40] Ma, C.; Beckett, J.R.; Rossman, G.R.: Buseckite, (Fe,Zn,Mn)S, a new mineral from the Zakłodzie meteorite, Am. Mineral., 2012 97, 1226-1233 DOI: DOI: $10.2138 / \mathrm{am} .2012 .4110$

[41]Xie, X.; Chen, M.: Suizhou Meteorite: Mineralogy and shock metamorphism (Springer geochemistry/mineralogy, Guangdong Science and Technology Press Co., Ltd., Guangzhou, China) 2016 pp. 64-85 
[42] Lennie, A.R.; Redfern, S.A.T.; Schofield, P.F.; Vaughan, D.J.: Synthesis and Rietveld crystal structure refinement of mackinawite, tetragonal FeS, Mineral. Mag., 1995 59, 677-683

[43] Rémazeilles, C.; Saheb, M.; Neff, D.; Guilminot, E.; Tran, K.; Bourdoiseau, J.-A.; Sabot, R.; Jeannin, M.; Matthiesen, H.; Dillmann, P.; Refait, P.: Micro-Raman spectra of FeS phases, J. Raman Spectr., 2010 41(11), 1425-1433 DOI: $10.1002 / \mathrm{jrs} .2717$

[44] Colomban, P.: Potential and drawbacks of Raman (micro)spectrometry for the understanding of iron and steel corrosion (in Ed.: Chiaberge, M.; New trends and developments in automotive system engineering, InTech Europe, Rijeka, Croatia) 2011 Chapter 28, pp. 567-584 DOI: 10.5772/13436

[45]Rickard, D.; Luther, G.W.: Chemistry of iron sulfides, Chem. Rev., 2007 107(2), 514-562 DOI: $10.1021 / \mathrm{cr} 0503658$

[46] Ren, C.; Li, D.; Bai, Z.; Li, T.: Corrosion behavior of oil tube steel in stimulant solution with hydrogen sulfide and carbon dioxide, Mater. Chem. Phys., 2005 93(2-3), 305-309 DOI: 10.1016/j.matchemphys.2005.03.010

[47] Smith, S.N.: Current understanding of corrosion mechanisms due to $\mathrm{H}_{2} \mathrm{~S}$ in oil and gas production environments, Nace Int., 2015 Corrosion Paper no. 5485

[48] Choi, H.J.; Al-Bannai, N.S.; Al-Beheiri, F.I.; Warnken, D.K.: Field corrosion assessment of 180 carbon steel downhole production tubing in Khuff gas wells, Nace Int., 2006 Corrosion Paper no. 6653

[49] Dehkordi, E.H.; Tavakoli, A.R.: The effect of time on the formation and growth of passive layer on carbon steel A516 GR.70 in sour water, Int. J. Iron Steel Soc. Iran, 2007 4(1-2), 28-33

[50] Shoesmith, D.W.; Taylor, P.; Bailey, M.G.; Owen, D.G.: The formation of ferrous monosulfide polymorphs during the corrosion of iron by aqueous hydrogen sulfide at $21^{\circ} \mathrm{C}, J$. Electrochem. Soc., 1980 127(5), 1007-1015 DOI: 10.1149/1.2129808

[51] Wikjord, A.G.; Rummery, T.E.; Doern, F.E.; Owen, D.G.: Corrosion and deposition during the exposure of carbon steel to hydrogen sulphidewater solutions, Corr. Sci., 1980 20(5), 651-671 DOI: 10.1016/0010-938X(80)90101-8

[52] Stringer, J.: Stress generation and adhesion in growing oxide scales, Mat. Corr., 1972 23(9), 747755 DOI 10.1002/maco.v23:9
[53] Singer, M.; Brown, B.; Camacho, A.; Nesic, S.: Combined effect of $\mathrm{CO}_{2}, \mathrm{H}_{2} \mathrm{~S}$ and acetic acid on bottom of the line corrosion, Nace Int., 2007, Paper no. 07661

[54] Sorell, G.; Hoyt, W.B.: Collection and correlation of high temperature hydrogen sulfide data, Corr., 1956 12(5), 33-54 DOI: 10.5006/0010-9312-12.5.33

[55] Backensto, E.B.; Drew, R.D.; Stapleford, C.C.: High temperature hydrogen sulfide corrosion, Corr., 1956 12(1), 6-16 DOI: 10.5006/0010-9312-12.1.22

[56] Meyer, F.H.; Riggs, O.L.; McGlasson, R.L.; Sudbury, J.D.: Corrosion products of mild steel in hydrogen sulfide environments, Corr., 1958 14(2), 69-75 DOI: 10.5006/0010-9312-14.2.69

[57] Anderko, A.; Shuler, P.J.: A computational approach to predicting the formation of iron sulfide species using stability diagrams, Comp. Geosci., 1997 23(6), 647-658 DOI: 10.1016/S00983004(97)00038-1

[58] Wagner, C.: Theory of the tarnishing process, $Z$ Physik Chem., Abteil B: Chem. Element. Proz., Aufbau Mater., 1933 B21, 25-29 (in German)

[59] Gulbrandsen, E.: Acetic acid and carbon dioxide corrosion of carbon steel covered with iron carbonate, Nace Int., 2007, Paper no.. 07322

[60] Silva, C.C.; Farias, J.P.; de Sant'Ana, H.B.: Evaluation of AISI $316 \mathrm{~L}$ stainless steel welded plates in heavy petroleum environment, Mat. Design, 2009 30(5), 1581-1587 DOI: 10.1016/j.matdes.2008.07.050

[61] Turnbull, A.; Slavcheva, E.; Shone, B.: Factors controlling naphthenic acid corrosion, Corr., 1998 54(11), 922-930 DOI: 10.5006/1.3284811

[62] Tebbal, S.; Kane, R.D.: Assessment of crude oil corrosivity, Nace Int., 1998, Corrosion Paper no. 98578

[63] Babaian-Kibala, E.; Nugent, M.J.: Naphthenic acid corrosion literature survey, NACE Int., 1999, Corrosion Paper no. 99378

[64] Kane, R.D.; Cayard, M.S.: A comprehensive study on naphthenic acid corrosion, NACE Int., 2002, Corrosion Paper no. 02555

[65] Hancock, P.; Hurst, R.C.: The mechanical properties and breakdown of surface oxide films at elevated temperatures (in Eds: Staehle, R.W.; Fontana, M.G., Advances in Corrosion Science and Technology, Plenum, New York, USA) 1974 Vol. 4, pp. 1-84

[66] Evans, A.G.; Hutchinson, J.W.: On the mechanics of delamination and spalling in compressed films, Int. J. Solids Structures, 1984 20(5), 455-466 DOI: 10.1016/0020-7683(84)90012-X 